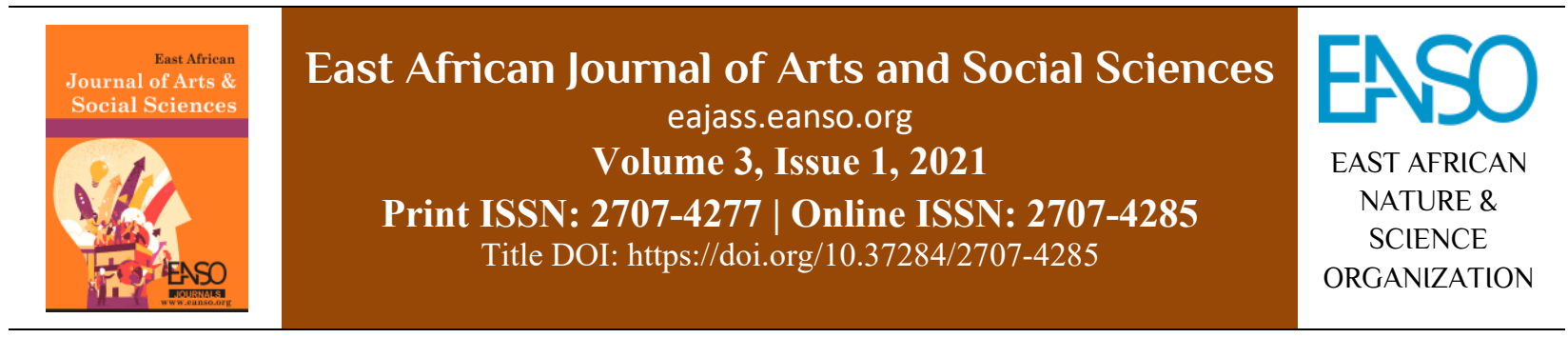

Original Article

\title{
'Drawing with my Students' - Development of Clothed Life Drawings among University Fine Art Students. Analysis of Selected Drawings by Second Year Students at Kenyatta University
}

\author{
Dr. Kamau Wango $^{1 *}$ \\ ${ }^{1}$ Department of Fine Art and Design Kenyatta University, P. O. Box 43844 - 00100, Nairobi, Kenya. \\ *Correspondence email: kamauwango@gmail.com.
}

Article DOI: https://doi.org/10.37284/eajass.3.1.291

\section{Article history: ABSTRACT}

09 March 2021 Students of Fine Art are introduced to drawing in their first year and human figure drawing in their second year. It is presumed that they have already had some element

Keywords: of earlier exposure in other levels of prior studies. The objective of human figure drawing or life drawing is to get the students to a level of applied skill where they can

Life Drawing, Model,

Observation,

Proportions,

Pencil Shading,

Anatomy disciplines of Art. This is because life drawing is a fundamental requirement in all disciplines of art from basic sketching to detailed paintings. This paper examines selected work of students to determine the extent to which they are able to achieve this objective within the unit prescribed duration of one semester. The paper also seeks to determine whether the work produced meets the standard of drawing required at this level which then enables the students to subsequently embark on other units of drawing moving forward. This is critical since they are required to apply their life drawing skills in other units as a matter of routine individual expression. In this regard, if they are required to draw or paint an imaginative composition, they would be expected to depict human figures which not only fit within the composition and are well executed but also express the students' ability to interpret themes and formulate subject matter. For the purpose of these exercises and in order to focus solely on the objectives of human figure composition and detailed development, the students were confined to the use of pencil for the layout, shading and detailing of their work. This is because pencil provides a wide range of manoeuvre for this kind of exercise. In this series of drawings, the students used one particular female model which provided them with the opportunity to visually interact with the individual model and be able to study and observe how the life model adjusts to various poses. This was designed to help 
East African Journal of Arts and Social Sciences, Volume 3, Issue 1, 2021

Article DOI: https://doi.org/10.37284/eajass.3.1.291

draw inspiration as well as make the drawing exercises methodical, enjoyable and purposeful.

\begin{abstract}
APA CITATION
Wango, K. (2021). 'Drawing with my Students' - Development of Clothed Life Drawings among University Fine A https://doi.org/10.37284/eajass.3.1.291

\section{CHICAGO CITATION}

Wango Kamau, 2021. “'Drawing with my Students' - Development of Clothed Life Drawings among University Fine”. East African Journal of Arts and Social Sciences 3 (1), 43-69. https://doi.org/10.37284/eajass.3.1.291
\end{abstract}

\title{
HARVARD CITATION
}

Wango, K. (2021) “'Drawing with my Students' - Development of Clothed Life Drawings among University Fine”, East African Journal of Arts and Social Sciences, 3(1), pp. 43-69. doi: 10.37284/eajass.3.1.291.

\section{IEEE CITATION}

K. Wango, “'Drawing with my Students' - Development of Clothed Life Drawings among University Fine”, EAJASS, vol. 3, no. 1, pp. 43-69, Mar 2021.

\section{MLA CITATION}

Wango, Kamau. "'Drawing with my Students' - Development of Clothed Life Drawings among University Fine”. East African Journal of Arts and Social Sciences, Vol. 3, no. 1, Mar 2021, pp. 43-69, doi:10.37284/eajass.3.1.291.

\section{INTRODUCTION}

Life drawing or human figure drawing remains a fundamental undertaking in any art discipline. All students need to be able to draw a human figure accurately and be able to internalize its proportions in order to apply it in any artistic dispensation, be it painting, sculpture, decoration or within the design disciplines. Ideally, when beginning from scratch, one begins with basic studies of contour or gesture line drawings and eventually builds his or her skill with the use of models and continuous drawing sessions focusing on various parts of the body. Drawing of the human figure is fundamental to artists because of its transcending essence across all art. It is undertaken as a basic study by artists across disciplines because 'the figure is truly the keystone of art' (Jordan, 2017). Life drawing is also undertaken because of its infinite inspirational value. Jordan (2017) observes that:

The human form holds a whole world of inspiration in its arms, legs, and torso. Whether compressed or sprawling, standing upright or arms akimbo, from exploring figure drawing proportions to focusing on that all-important gesture of the body, there is always something to delve further into if you take the figure as your subject. 
Plates 1(a-e) - Quick pencil sketches by Author (2020)

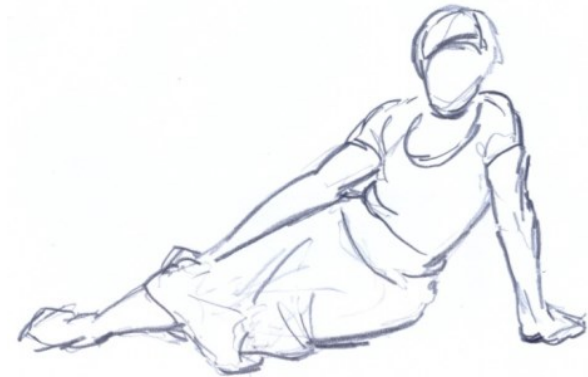

Plate 1a: Propped-up, front view

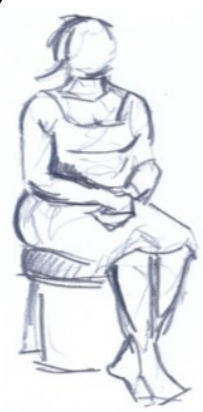

Plate 1b: Seated

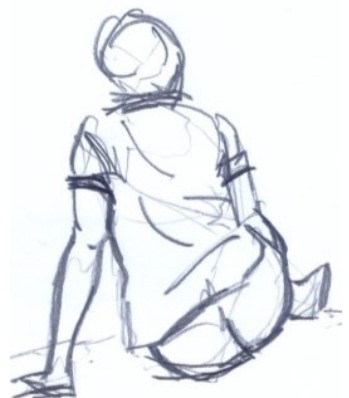

Plate 1c. Propped up, back view

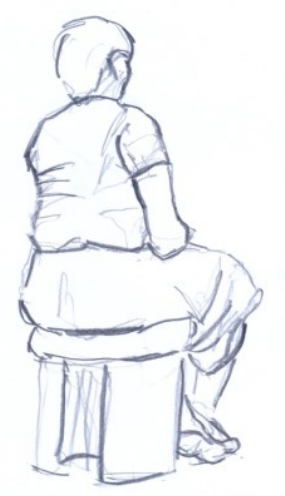

Plate 1d: Seated figure

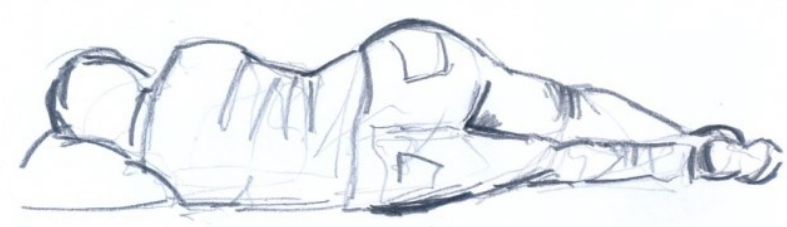

Plate 1e: Reclining figure

At the beginning of the exercises, students were introduced to quick two minutes pose drawings (similar to gesture drawings in approach but do not deal with spontaneous gestures, but deliberate poses) where the objective was to capture the feel of the pose and body posture and to quickly capture 'suggestive proportions' (Plates $1 a-e$ ). They do many of such drawings to focus their eyes on quickly identifying pertinent aspects of the body that constitute the pose, and isolate suggestions of proportions as the eye flashes over the model. Suggestive proportions here refer to the proportions captured by the eye as it combs over the model without capturing any details. Subsequently, the quick movement of the artist's hand captures only a passing 'suggestion' of the proportions of the various body parts as they manifest themselves. It became evident that the more the students were able to capture suggestive proportions in flashing moments, the more they became 'aware' of these proportions. They were able to ultimately focus their attention upon the same parts when they embarked on drawing figures for which they had more time. This helped them to generate a better visual gauge of proportions that underscored the particular pose. 


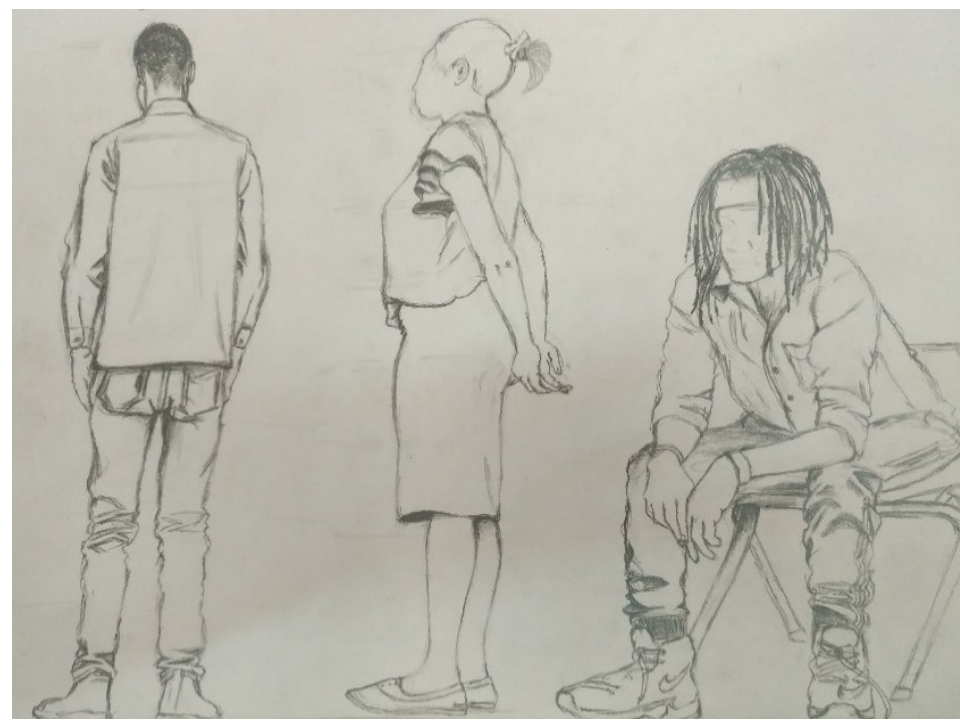

Plate 2a: Layout line drawings

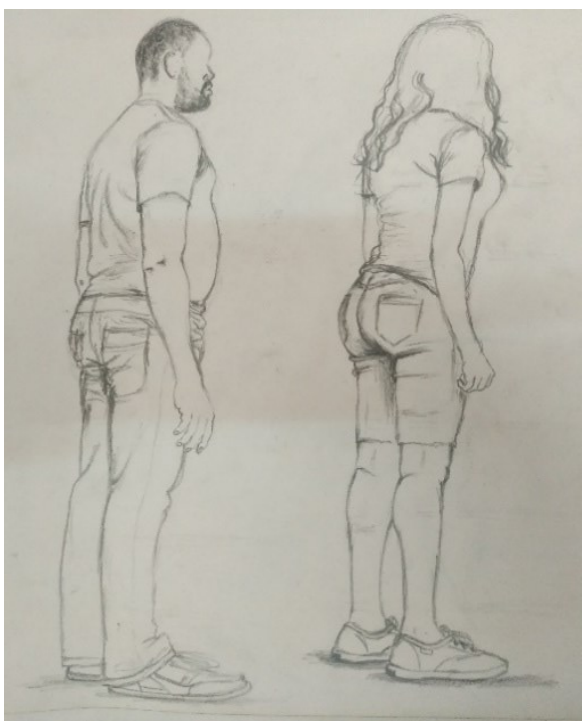

Plate 2b: Layout line drawings
After the quick pose drawings, the student artists embarked on line drawings that were based on a variety of poses by different student models (Plates $2 a \& 2 b$ ). These were allocated more time (about half-hour), to lay out the figure and capture proportions with only minimal details. This was designed to help them focus more on the nature of proportions and how they actually interrelate in the construction of the entire figure, where the entire body frame is deemed visually acceptable, not necessarily perfect. It is notable from the line drawings that the student artists demonstrate the ability to 'feel' and hence adequately observe the body posture and to use clothing to help them segment the figure in order to work out proportions.

It is important to note that proportions are themselves basically defined by the various joints in the human form which become the points of reference in the way the eye perceives the construction of proportions. The placement of joints is constant since it defines the functionality of the entire body design; when there occurs a visual displacement of these joints, then the figure will appear invariably strange and distorted. These joints help one to work out the distances between parts of the body that eventually construct proportions as they are known and accepted. There are joints in the neck, shoulders, elbows, wrists, pelvis, knees and ankles. Medlej (2013) notes that "a wellproportioned figure, regardless of variations due to gender or such, is defined by the alignment of the joints, which is invariable (that is, we perceive something odd if it does vary)."

\section{The Notion of Visual Logic in Human Figure Drawing}

The use of a model still remains a most useful avenue for human figure drawing because it gives students the opportunity for visual engagement with the model through continuous observation. Continuous observation is the best form of visual referencing because the model is living and real. Ultimately, this visual engagement leads to the comprehension of the construction of proportions in what this paper terms as 'visual logic'. This simply means that students start to connect that there is a definitive manner in which one part of the body relates to another and that this relationship remains logical and constant. Once students internalize the notion of visual logic as it applies to the construction of proportions, then they understand why their figure drawings appear 'funny' or distorted and need to be rectified when they do not meet this threshold of visual sense. For instance, it is visually illogical for one hand to be longer than the other in a straight standing figure, or for hands to fall below the knee line. It does not make structural sense for feet to be too small to support the body weight, or for hands to be too big for the arms. Whenever students draw, they are constantly looking out to ensure that they attain this visual logic in the way parts of the body interrelate. Indeed, when one wishes to abstract a human figure or a 
human form, what they are in essence doing, is to discard this visual logic and break down the norms of proportions to create a new creature.

Within a prescribed timeframe for each drawing exercise, this paper studies the application of this notion to bring students' attention to the interrelationships in proportions that they must endeavour to capture correctly through observation. It also presupposes that the students already realize that a living person cannot be the human being they are if they do not bear a certain definitive manner in which their body proportions are constructed. Any distortion of these relationships puts this beautiful balance in disarray and transforms the human being into some form of humanoid that bears no visual logic. The actual purpose of life drawing is to ensure that this beautiful visual description of a human being is observed and not desecrated. If one tries to give this figure a disproportionate head, neck, shoulders, arms or legs, then what one creates is bizarre and grotesque.

\section{DESCRIPTION OF HUMAN FIGURE DRAWING}

Human figure drawing, often referred to as life drawing, is the drawing of a human form through the observation and careful study of the parts and the proportions that constitute it. The human form is as complex as it is beautifully crafted. The drawing is usually carried out in stages, following the principle of simple to complex; beginning with the fundamental quick one-minute sketches to very detailed sketches that take hours or more to finalize. These initial quick sketches help in capturing the main joints of the figure that define the functional demarcation of parts and which in turn denote movement. These are followed by contour line drawings and gesture drawings that are more inclined towards poses and gestures that must be captured rapidly either because the subjects of observation are transient or the model cannot sustain the intricate poses for too long. These gesture drawings are critical in building up observational skill that enables students and artists to quickly capture proportions as they flash through their eyes within a limited amount of time. With the eventual internalization of proportions, the artist is able to embark on more detailed studies based on more focused referencing upon the human anatomy that includes bone structure (skeletal perspective) and muscle formation (muscular/tissue perspective). Both of these show the interrelationships of parts, their functions and their proportions. Ultimately the student/artist is able to utilize a model (real-life reference) as the focus of observation that provides an opportunity for reallife or 'realistic' study of the human form. In defining the skill of observation, Li (2019) observes;

Looking is different from seeing. Looking at things is easy, but seeing is harder. We can easily look at a model and know that it's a model. But seeing means understanding the model's body, knowing where the muscles are, how the body is rotated, where the shadows and lights are, the proportions and relationships of parts of the body, the angle at which the head is tilted etc. By seeing, we can draw with more detail.

As already noted, human figure drawing using a model is important in internalizing how body parts relate and how proportions are themselves logically constructed in the process of drawing. The human body emanates movement in many aspects and this movement is aided by functional parts that constitute coordinated synchrony. This, therefore, means that parts are calibrated to fit in the entire body movement processes and, hence, have defined shapes and proportions. This is what a good artist seeks to observe and render in life drawings. The whole motivation of life drawing (using a real-life reference) is to create a drawing that emanates the notion of a 'living person' not a static manikin. Mitchell (2013) notes that:

Human movement requires a lot of cooperation from each of the body parts, and seeing this in motion during a life drawing session can give an artist a sense of what actually goes into a movement. They will be able to see how a body works together to perform specific movements and replicate it in their own works

\section{Human Figure Drawing and its Usefulness in Artistic Expression}

Artistic expression in many genres is by and large undertaken through the depiction of human figures. This has been evident through the ages where the human figure remains the most profound tool 
though which artists have used as a convergence point or reference point of their self-expression or social commentary. Human beings, of course, always wish to use something that is cast in their image to portray themselves, their fears, their joy, their indignation as well as their hopes. This visual expression by artists has been evidently executed through facial expression, gestural expression, body distortions, abstraction, depiction of emotions or any aspect of human description that is expressible through the human figure.

Life drawing gives students the opportunity to gain insight into the rather complex body movements through the flexibility and coordination of body parts as seen through the model. The study of the various parts of a living person introduces the element of reality and fluidity; that these are actual components of a human body that function in an extremely coordinated manner and hence the need to capture their structural interrelationships and proportions. When this is done correctly, then the student or the artist is able to create a human figure that bears visual integrity, is convincing and which in application to a given composition, becomes relatable and generates a degree of empathy. The study of the face and gestural postures opens the opportunity for the depiction of emotions that are important in human/artistic expression. This ultimately improves the quality of students' expressive work. Swinton (2018) notes;

While rendering the figure, an artist is able to witness how the entire body reacts when certain characteristics are present, including posture changes and gestures which can help them evoke an emotion in their own pieces.

Life drawing is useful in terms of getting a better grip of human anatomy by understanding the musculoskeletal anatomy or the relationship between the skeletal system and the muscular system. A live model provides the opportunity to holistically observe this relationship. Students, of course, will not 'see' the bones but can tell how the bone structure hidden underneath the skin influences the muscles within the body tissue. The muscle structure itself helps to define the shapes of the body parts; for example, a female or male arm derives its shape both from the underlying bone structure and more importantly from the muscle composition and its connective tissues. Hence an arm, or indeed any part of the body, will seem to bulge and thin out or 'undulate' according to heavy muscle placement, points of tension and joints that determine movement and weight balance. A static study of the skeleton or anatomical layout of a body is good but not artistically adequate. It has to be augmented by a life drawing to observe how the two work in reality, particularly in regard to movement and changing poses. $\mathrm{Li}$ (2019) observes that;

Learning the individual bones and muscles are important, but you may be unable to visualize how they look in various poses. During a life drawing session, as the model poses, you will be able to have a better understanding of how the muscles and bones interact with each other, how the muscles look when tensed or relaxed in different angles etc.

Human figure drawing is also extremely useful for concept development in art, where artists have to work on the development of characters that propagate a given narrative.

\section{Clothed/Nude Figures}

Human figure drawing can feature either unclothed (or nude) models or clothed models. Artists have their arguments in favour of either of the two, so it boils down to being a matter of informed choice; either preference, circumstance, cultural, environment or artistic objective of the moment. In arguing the case for the unclothed figure, Jordan (2018) observes; -

There will always be a place for drawing the figure with nothing shielding it from our gaze. Unadorned, the body is at its simplest and yet its most sophisticated. Presentations of nude figures allow an artist's skill in anatomy to shine through. The figure often becomes about gesture and action and less about individuality.

But in presenting reasons why clothing may also contribute to better human figure drawings, Jordan (2018) also observes; -

With these, you immediately get a sense of personality, of attitude. Constricting or tightfitting clothing may parallel or visually represent the psychological complexities and 
internal conflicts within the figure - and within us all. And sometimes clothing is just about representing a person at a specific place in time: a slice-of-life depiction that is all about seeing the people around you frozen in a moment.

In this series of drawings by students, the clothed model presents the kind of additional challenge that would be useful for student artists as they prepare to utilize their life drawing experience for expressive purposes in other disciplines of art. In these dispensations, the adornment of attire becomes a major component in the suggestion of individuality, character and culture and plays a critical role in the theatre of subject matter and interrogation of themes. Apart from the study of the human body itself as physical entity, the study of the clothed body is fundamental in the study of cultural and other expressive human narratives. In terms of the usefulness of its own visual rendition, the depiction of attire is important in terms of emphasis of body posture, poses, body motion, gestures, and emotions; particularly through the application of the effects of shading.

\section{ANALYTICAL FRAMEWORK}

In analysing human figure drawings by student artists using a clothed model as in the case of this paper, one looks out for the following:

- The distribution of weight as a tool for the study of posture and pose.

- The suggestion of movement.

- The study of proportions and their interrelationships.

- The synchrony with hidden anatomy.

- The use of pencil shading as a tool for emphasis of details.

- The study of likeness.

- The depiction of attire.

- Evidence of focused observation.

\section{Distribution of Weight as a Tool for the Study of Posture and Pose}

The human body as a piece of creation is already superbly aligned; it has a perfect weight distribution all the way from the head, the arms, the torso, down to the legs that makes it stable, irrespective of movement, twists or stretches. In drawing a human figure, one is fundamentally observing this weight distribution in the study of proportions in whichever pose the figure may be presented. This is referred to as 'posture' and ensures that not only does the figure seem to reflect stability in the real physical sense of it, but it does so visually as well. One of the most often used examples of the effectiveness of weight distribution is the functional role of feet. The feet carry the weight of the entire body such that the body does not tip over. The weight distribution, of course, is spread through other parts of the body structure or skeletal armature, like the pelvis bones, the thigh bones, knees and lower legs. When drawing proportions, any misrepresentation of these proportions, including the alignment of the spine, denotes an interference with weight distribution which means that the figure appears misaligned and, therefore, wrong. The more students are aware of this existing body alignment, the more their drawn figures look convincing and relatable.

\section{Suggestion of Movement}

A human figure by its own description is not static; it denotes movement. The human body itself is a complex entity that is composed of many interrelated parts that coordinate to emanate the functional ability of the body. When drawing a human figure, it is important for it to depict this sense of movement, particularly in its various poses and gestures which underscore the functional role of body parts. The more effectively the proportions of parts of the human figure are observed and depicted, the more the indication of movement is rendered tenable and convincing.

\section{The Study of Proportions and Their Interrelationships}

Drawing the human figure is fundamentally about getting proportions right. The human body is well configured and a good human figure drawing is one that captures these proportions appropriately through good observation. In order for student artists to depict this visual beauty through accurate proportions, they first have to internalize how parts of the human body function and interrelate.

\section{The Synchrony with Hidden Anatomy}

The human body bears musculoskeletal anatomy. The bone structure and its muscle attachments are 
the basis upon which the body functions in terms of posture and movement. Without this structural anatomy, the human body would collapse. When drawing, the student cannot see the bone structure, muscles or tendons but they can comprehend the idea of the skeleton as an armature that guides their drawing. When this is borne in mind when drawing proportions, then the figure drawing is bound to be well articulated. For example, when drawing a leg, there is need to study the distances between segments of the leg as dictated by the femur and tibia bones and the muscle tissues that surround them. But there are the visible muscles of the legs that are as a result of this structure and which form the outer shape of the leg that makes it recognizable. The synchrony with the entire bone and muscle structure of the body, hence, becomes an important guide to the holistic human figure drawing.

\section{The Use of Pencil Shading as a Tool for Enhancement of Details}

When using pencil or any other suitable medium, the application of shading is used to enhance the drawing in terms of detailing, depiction of texture, usage of light, variation of tones, and application of shadows with the purpose of making the drawing come to life as well as giving it a three dimensional or rounded appearance. The more effectively the shading is rendered, the more convincing the drawing becomes and the more the proportions and the shapes of the parts of the body are articulated.

\section{The Study of Likeness}

As students learn to draw, the depiction of likeness is not always required in the formative stages.
However, the concept of likeness if fundamental to human figure drawing as they gain skill and confidence; since that is what one wishes to capture in the same way that one wishes to capture the visual description of the respective model's body. Ultimately, the need to capture likeness, just like in portraiture, is a key aim of life drawing; there is no model without individual facial definition or suggestion of innate character.

\section{The Depiction of Attire}

In clothed human figure drawing, the depiction of the nature of attire helps to describe the figure itself, its posture and movement. It is executed through application of shading or colour tones in the case of painting. Shading helps to bring out the folds which in turn suggest the direction of body movement, shifts and twists of the body, stretching of the body or folding of the body. Folds also help to emphasize gestural poses.

\section{Evidence of Focused Observation}

A well-rendered human figure drawing is always a result of focused observation. Focused observation means that the student is aware of what to look for. When a holistic study of the human figure depicts good proportions, for instance, it implies that the student artist was able to pick out the intricate interrelationships between the various parts of the body which only comes with keen, purposeful observation. 


\section{ANALYSIS OF WORK}

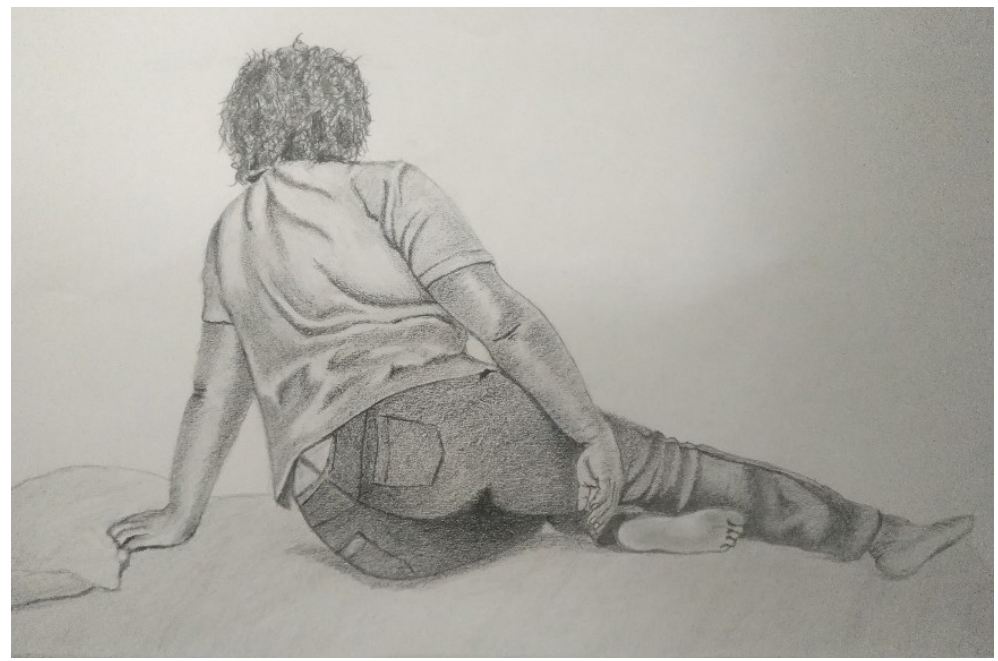

Plate 3: Alex Kariuki (2020)

'Propped up pose'

Pencil - 29 x $42 \mathrm{~cm}$

The back pose of the propped-up position is unique and gives the student artists the opportunity to capture the body structure from a pose that they would often not select. Plate 3 shows the detailed study of the back/side view showing the study of proportions as they manifest in this position. The student artist captures a generally accurate figure that underscores the physical character of the female real-life model. The drawing is developed with shaded folds that help outline the posture and emphasizes pertinent parts with both light and dark

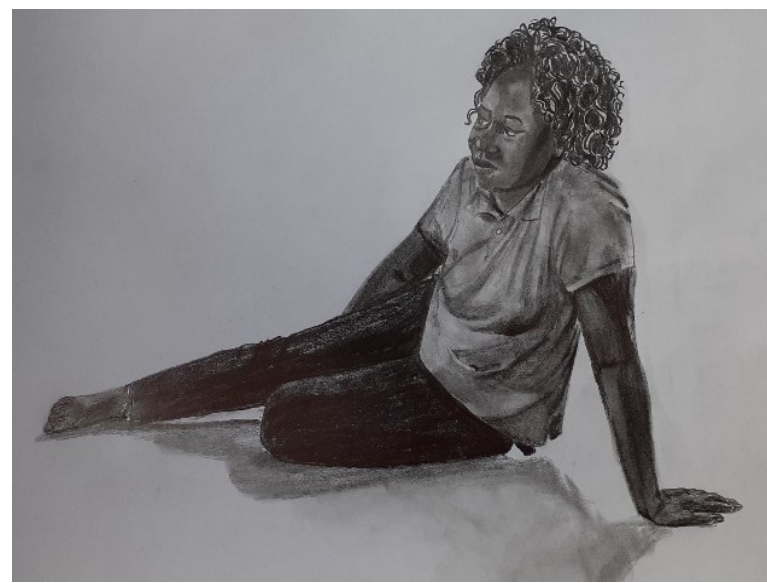

Plate 5: Mercy Mwikali (2020)

'Propped up front pose'

Pencil - 29 x $42 \mathrm{~cm}$

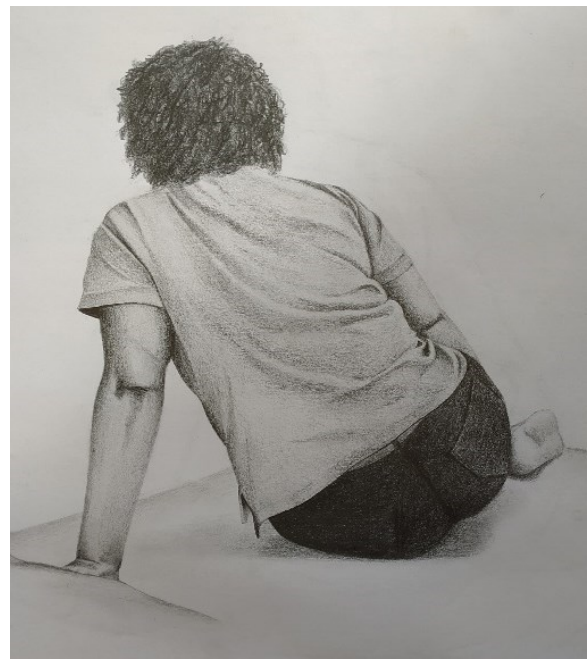

Plate 4: Mvoi Kigondu (2020)

'Propped up pose'

Pencil - 42 × $29 \mathrm{~cm}$

tones as well as shadows. Plate 4 is a study of a direct back pose that also accurately depicts the proportions of the figure propped up and resting on the left hand; the right hand is only just visible. The student artist studies and captures the folds through shading that suggest body swing towards the left side exerting entire body weight on the left hand. It is also notable that the student artist studies the elbow that becomes a focal point of this pose and shows that the elbow acts as the pivot from where the weight is distributed.

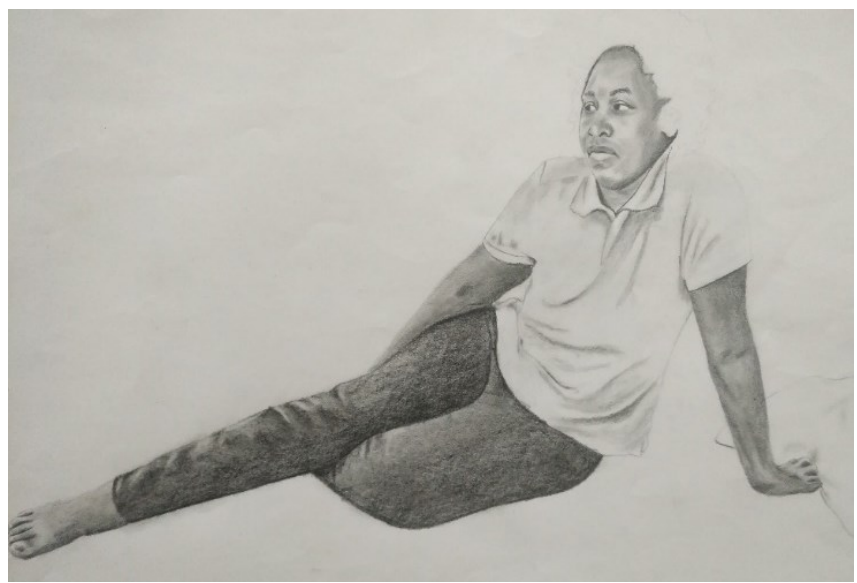

Plate 6: Edgar Keng'ara (2020)

'Propped up front pose'

Pencil - 29 x $42 \mathrm{~cm}$ 
In the same setting, the student artists examine the front pose. In plate 5, the student artist captures the front view of the same model. The pencil shading is well executed and shows the pertinent angle of the pose through the folds, variation of tones and use of shadows. The student also takes time to study the face and texture of the hair in a way that makes the model identifiable. Plate 6 shows how the student artist lays out his work and gradually consolidates it into a pleasant piece of drawing (Plate 7).

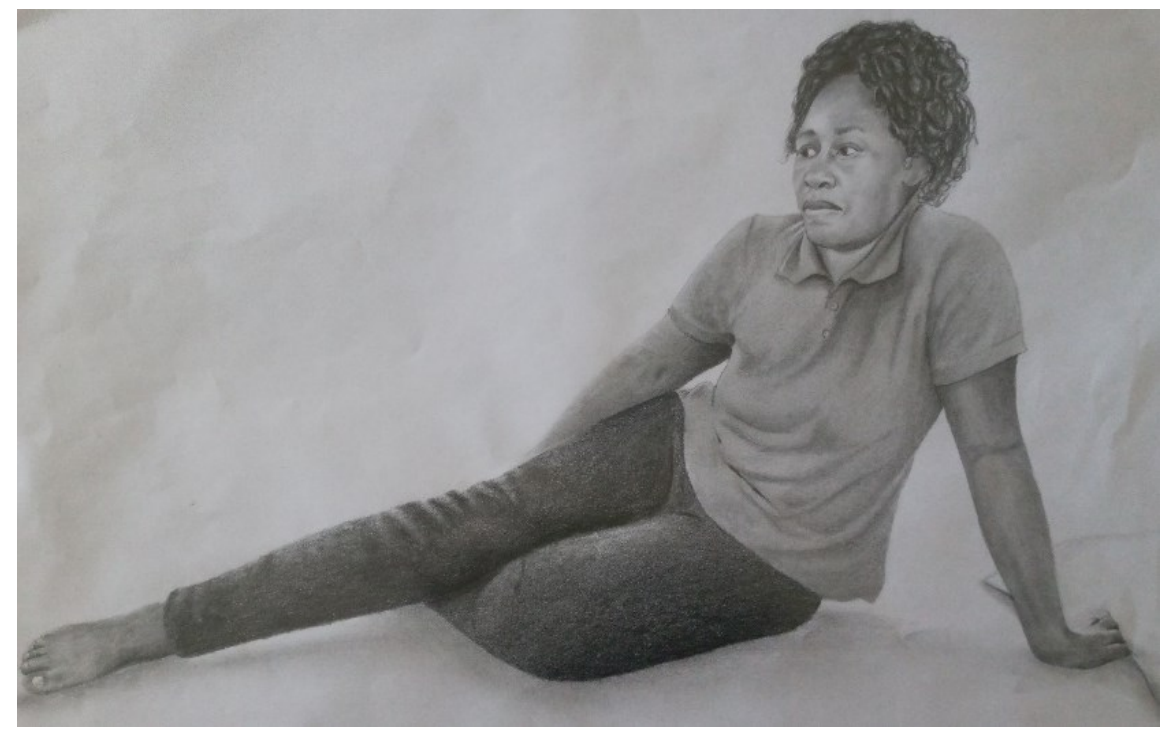

Plate 7: Edgar Keng'ara (2020)

'Propped up figure'

Pencil - 29 x $42 \mathrm{~cm}$

The student artist captures the model in a proppedup position, with the upper body supported by the left hand (Plate 7). The proportions are well articulated and are augmented by the application of very pleasant pencil shading that helps suggest the body swing as it stretches to accommodate the pose. This is shown by the folds on the T-shirt. The student artist also studies the model's face serene expression and curly hair texture. The student artist also displays awareness of falling light and the various spots upon which it illuminates the figure. This is a beautifully executed study that not only captures the figure aspect but also portrays the 'personality' of the model.

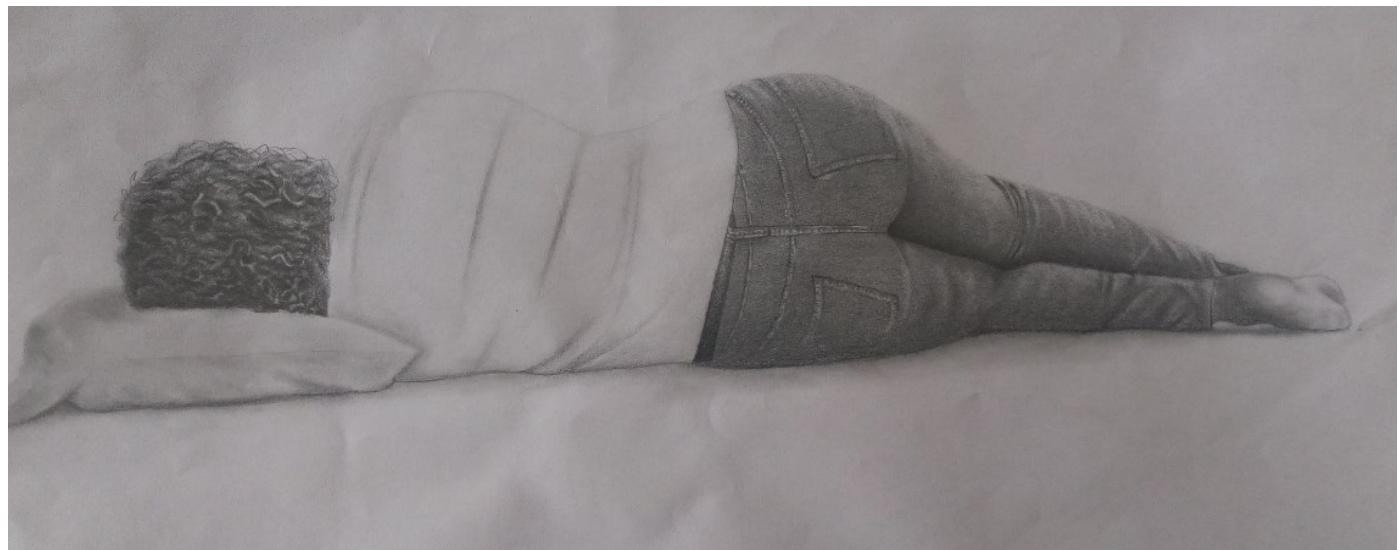

Plate 8: Edgar Keng'ara (2020)

'Reclining figure'

Pencil - 29 x $42 \mathrm{~cm}$ 
The student artist captures the undulating features of the body profile of the reclining figure (Plate 8). From the initial line drawing, he follows it up with convincing lightly applied pencil shading that depicts the curly texture of the hair, the tight folds of the white top and the folds of the tight jeans that help outline the reclining posture. It is pleasant to note that the student artist takes time to study the details of the jeans including the pockets, stitch lines, the almost soft tightness that outlines the model's figure, suggestion of shadows and the effect of the falling light as well as folds as they occur in certain places.

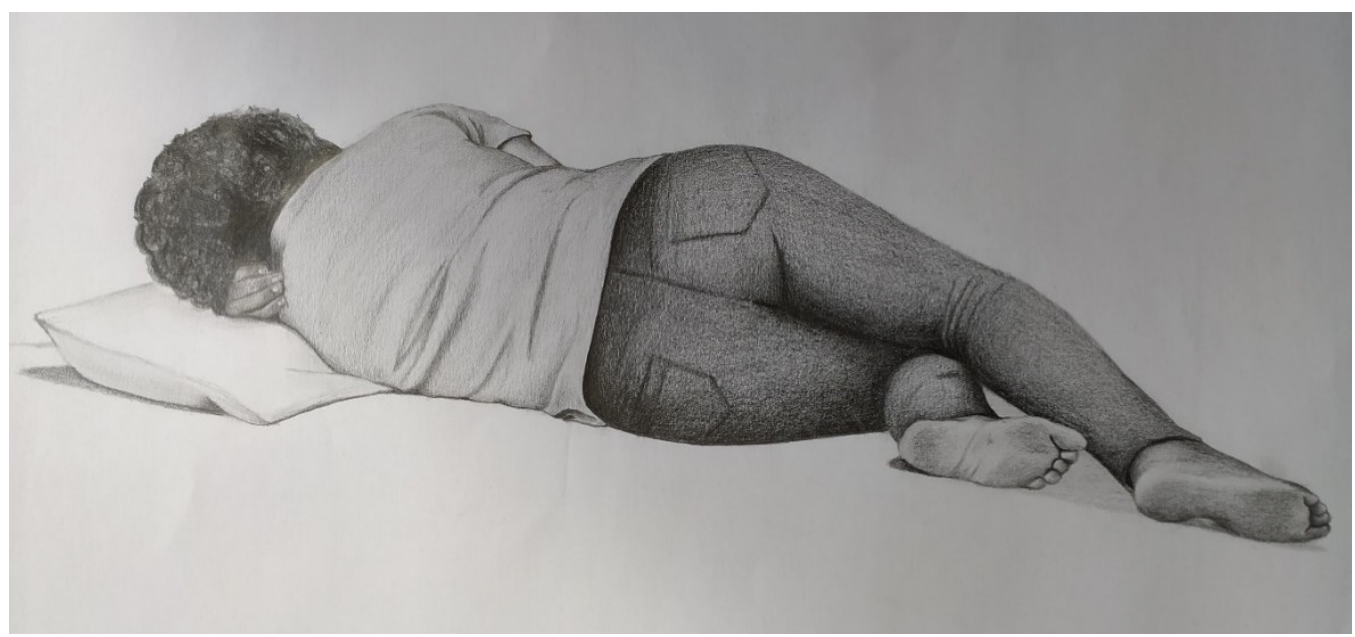

Plate 9: Mvoi Kigondu (2020)

'Reclining figure'

Pencil - 29 x $42 \mathrm{~cm}$

In Plate 9, the neatly executed drawing captures the reclining figure and its undulating effect that portrays the shape of the body and captures details of the pose including the hand tucked under the head. The student artist displays awareness of the foreshortening effect on the folded left leg and portrays the details of the feet, demonstrating that he is aware of how foreshortening is applied in order

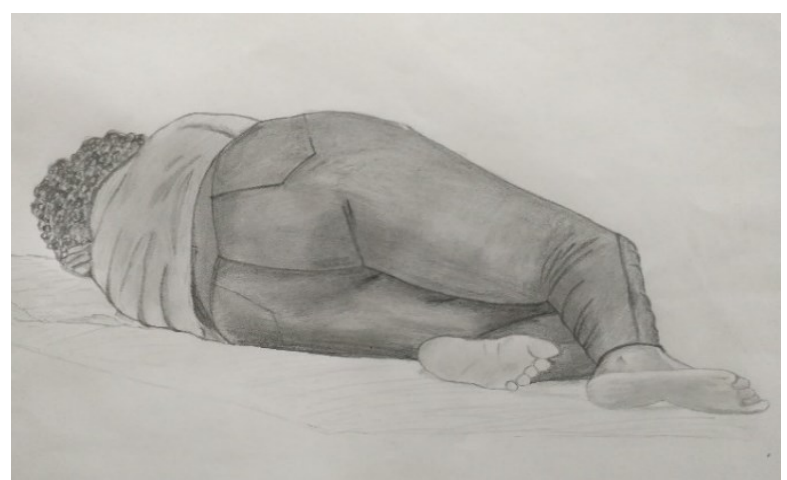

Plate 10: Ng'aru Brian (2020)

'Reclining figure'

Pencil - 29 x $42 \mathrm{~cm}$ to maintain the proportion and visual stability of the entire figure The shading displays good application of pencil effects and variation of tones that help emphasize certain body parts and create a sense of roundness and solidity. He also uses pencil to depict texture of the hair, the woody tight jeans, folds on the attire as well as falling light and shadows.

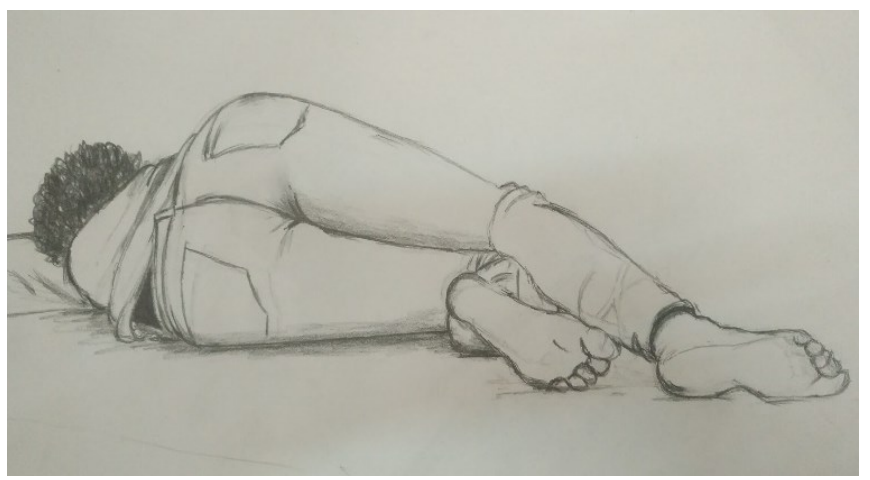

Plate 11: Stanley Muga (2020)

'Reclining figure'

Pencil - 29 x $42 \mathrm{~cm}$ 
In Plate 10, the student artist lays out the reclining figure from a side/back angle necessitating a slight foreshortening effect and application of perspective, but which still quickly captures the pose quite accurately. Plate 11 is a line drawing which shows that students are often able to capture a given pose by emphasizing the pertinent parts of the figure. This student artist captures the bulging buttocks as the 'prominent part' of the mid-figure from the angle of his view, and then captures the foreshortened folded leg and feet on one end, and the diminishing upper body and head on the other end culminating in a figure that is not only lying but literally collapsed on the mat. Students are encouraged to explore such boldness of observation which eventually helps then to internalize the dynamics of proportions very well.

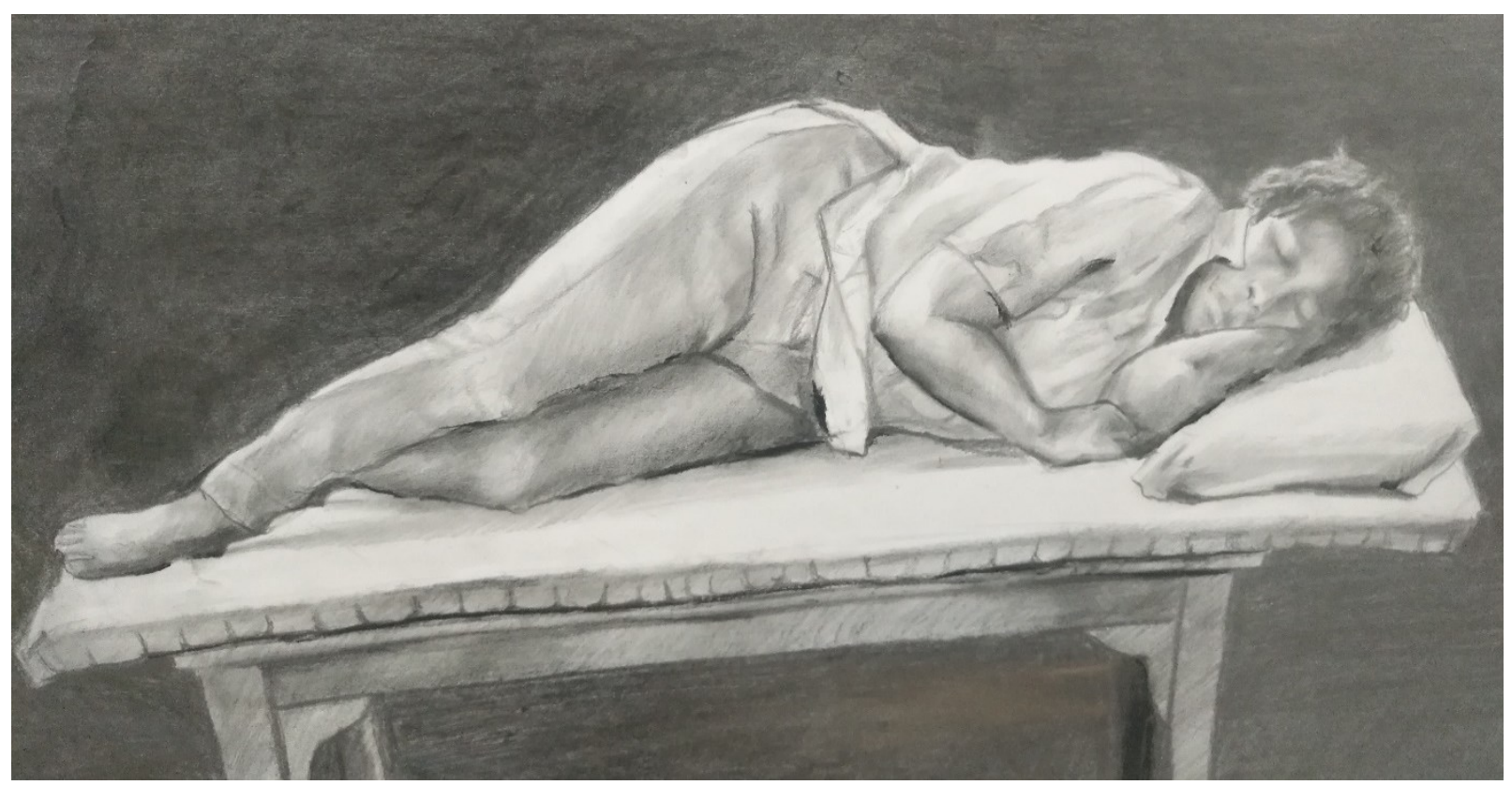

Plate 12: Samuel Muiga (2020)

'Reclining figure'

Pencil - 29 x $42 \mathrm{~cm}$

In the reclining figure (Plate 12), the student artist boldly captures the model's lying posture defining her body profile. After first laying out the line drawing, the student applies pencil shading showing variation of tones and particularly the effective use of background contrasts and the effect of falling light illuminating the various parts of the figure. Detailing includes portraying the drowsy face placed on one arm for comfort, the shape of the folded right arm that helps underscore the tucked-in pose as well as the use of folds and emphasis of shadows. The drawing gives the model her identity which is a major objective of life drawing. The completed face gives the entire figure its visual essence which suggests the model's individuality and character. It is evident that the student artist took time to capture the likeness of the model's face. 


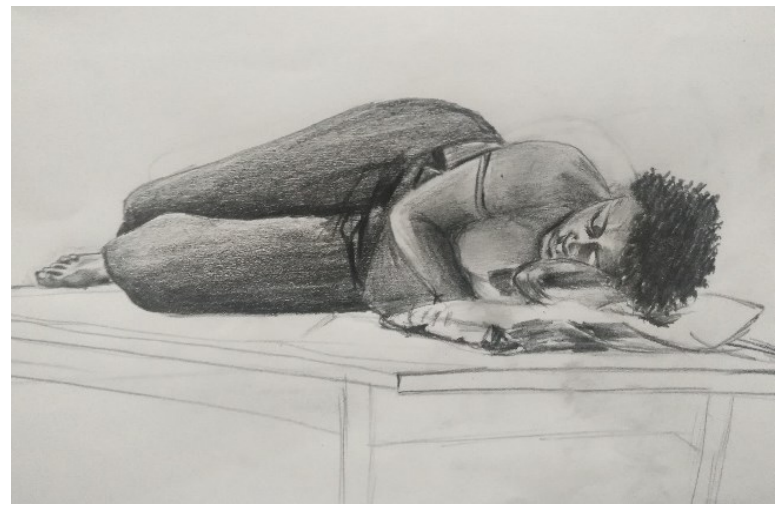

Plate 13: Stella Qnguti (2020)

'Reclining figure'

Pencil - 29 x $42 \mathrm{~cm}$

Both the drawings in Plates 13 and 14 show the reclining figure from a rather difficult head down angle but both student artists render their drawings very well, capturing the body profile and studying the fundamental apects of the reclining pose that define the figure. In Plate 13, the student artist consentrates on the use of pencil tones, shadows and focusing light on parts of the body in order to portray the body profile. In Plate 14, the student artist uses aspects of foreshortening to lay out the

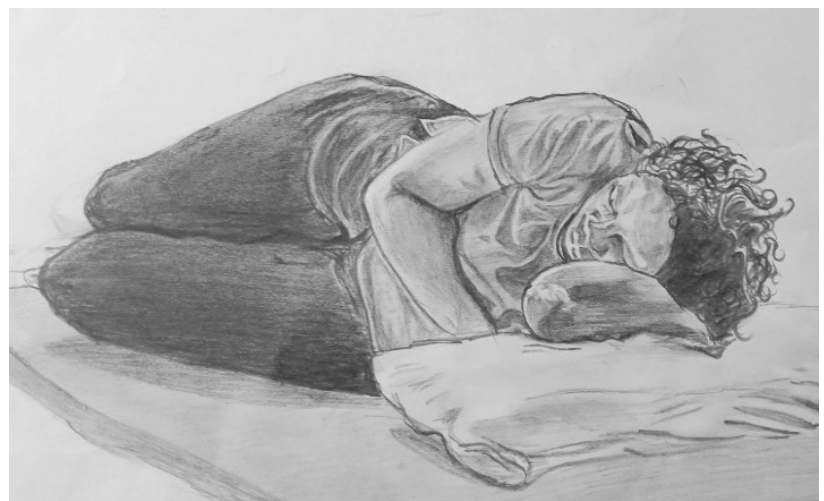

Plate 14: Ruby Moraa Rasugu (2020)

'Reclining figure'

Pencil - 29 x $42 \mathrm{~cm}$

figure and uses interesting pencil tones to create folds on the model's blouse that depict the twist of body posture. Despite the diffuculty of angle, the student studies the body profile and the expression on the sleeping face and captures how it rests on the folded forearm and pillow. The right arm is folded into position to add comfort to the model. She uses shading to develop the rest of the drawing including the curly hair and use of shadows that depict the figure resting on a surface.

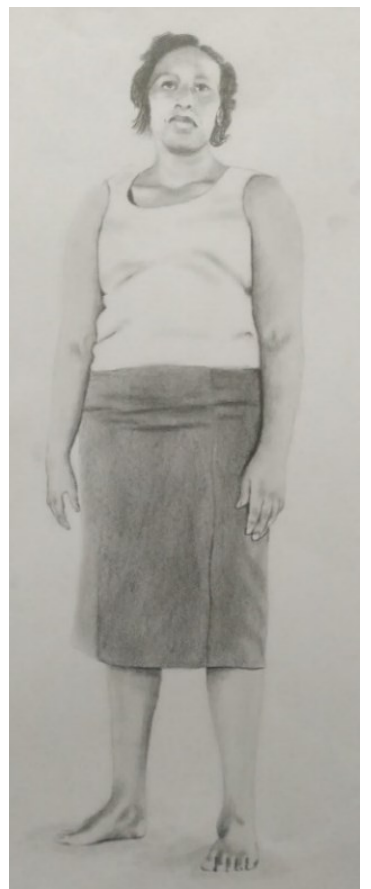

Plate 15. Edgar Keng'ara (2020)

Standing pose,

Pencil - 42 × $29 \mathrm{~cm}$

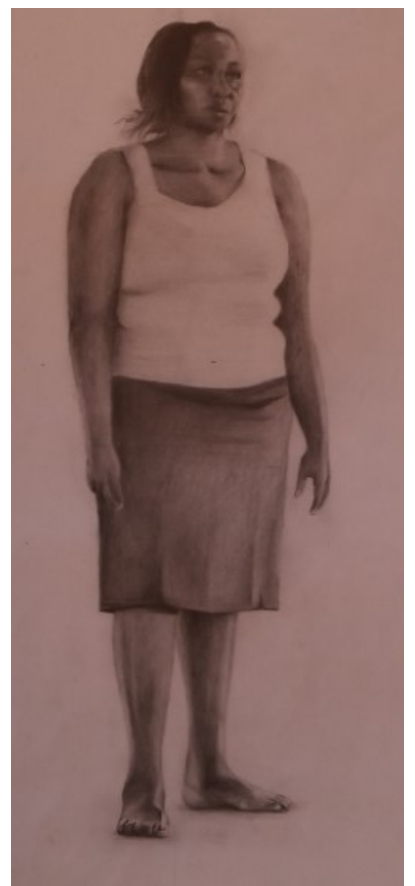

Plate 16. Chris Barr (2020)

Standing pose'

Pencil - 42 × $29 \mathrm{~cm}$

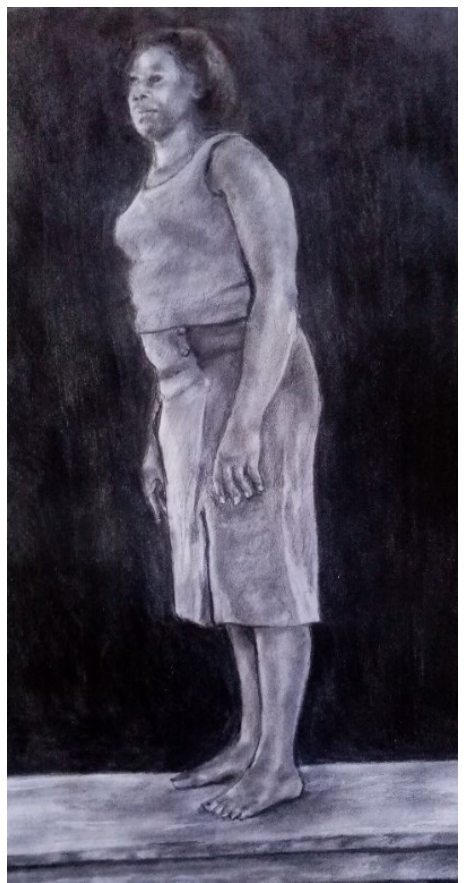

Plate 17. Samuel Muiga (2020)

Standing pose'

Pencil - 42 × $29 \mathrm{~cm}$ 
The student artists found the popular standing pose challenging but interesting to observe and study. In order to initially grasp the structure of the human figure, the students were required to draw both the male and female human skeletons. This was deemed necessary for them to internalize the bone structure because it forms the skeletal armature of the human body. However, as has been observed before, the emphasis of the exercises was to focus on observation based on the functions of the various parts that informed their interrelationships. This implied that there was a logical way in which parts relate which dictated their proportionality relative to each other. Student artists found this argument fascinating when their attention was drawn to the simple visual and functional fact that shoulders cannot prolong or decrease beyond a certain point relative to the neck; and that for instance, the arm cannot stretch to the knees otherwise the figure would appear gawky and apelike! Hands cannot be too small compared to the arm otherwise they would lose their graping ability; and feet cannot be too small to support the body frame or be too big to cause the body to waddle along. With this in mind, the student artists were also introduced to the concept of eight segment head lengths within which a human figure generally fits in terms of composition. They worked out that the length of the head runs down approximately eight times down the length of the body. Since the model was clothed, students were advised to work out their proportions based on the various cues provided by the model's attire. Hence, they were told to pay attention to the size of the head, the size of the neck, the stretch of the shoulders, the length of the arm, its shape and relationship to the size of the hand. Their attention was also drawn to the waistline, the hips, thighs, the kneeline, lower legs, ankles and feet. Though the student's artists were introduced to the basic aspects of the masculoskeletal human anatomy, they found this too complicated and wanted to rely more on their visual/observational acumen.

In Plate 15, the student artist captures the figure with commendable accuracy and takes time to study the face as well. The drawing shows how attire can help guide basic proportions which is an approach that all students tended to use in drawing this particular female model. In Plate 16, the rendering of the drawing shows good observation of pertinent details but hands are a little small for the body. In Plate 17, while the drawing is quite a well-executed study with good pencil shading, the student artist did not take note of body posture and the alignment of the spine, hence the drawing is tipping forward. The illuminating effect of light upon the body and the sharp contrast to the background, however, takes the eyes away from the posture since it is very well executed. This student artist applies chiarascuro as a technique to emphasize his figure drawing but also goes on to apply details using pleasant pencil tones. In all three standing figure drawings, it is apparent how the student artists use attire to help them work out the entire body proportions. As they observe, it is convenient to visually measure distances and eventually each body part against the other. 


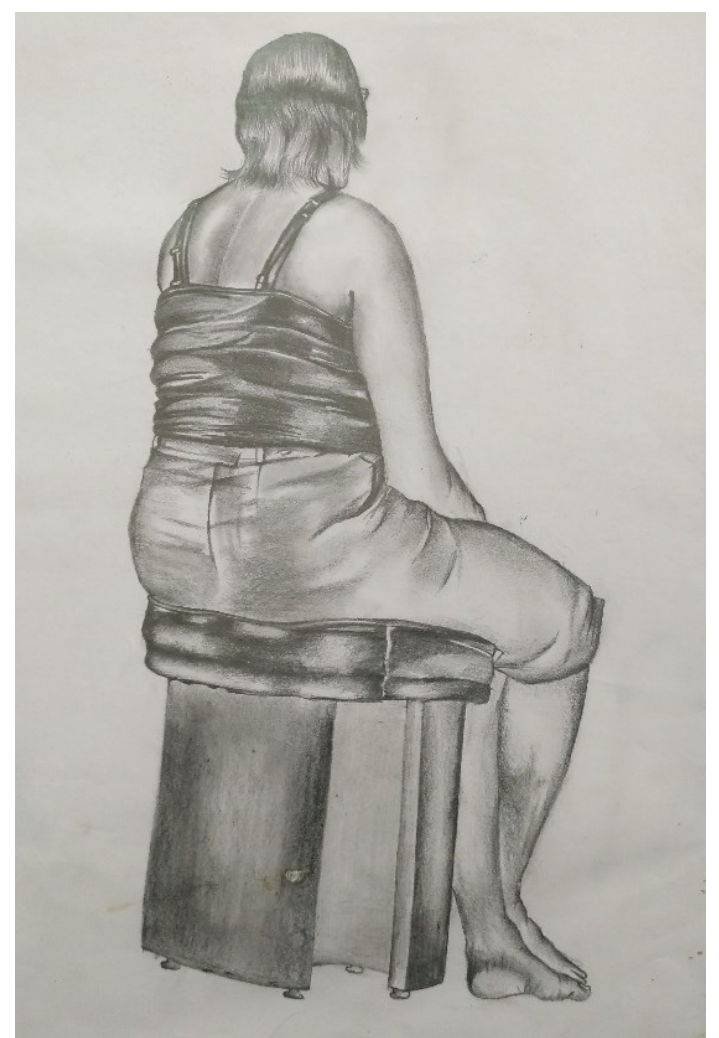

Plate 18: Brian Olago (2020)

'Full figure Seated pose'

Pencil -42 × $29 \mathrm{~cm}$

The simple seated figure on a padded studio pouf is popular but challenging. The idea was to observe proportions in a seated pose to capture the model's body structure in this pose. The student artists were encouraged to capture details of the facial likeness of the model. The body structure is critical in all poses and the student artists are expected to demonstrate their ability to observe and capture the essence of that structure at all times, whichever way it is presented. The back angle (Plate 18) displays an accurate study of the model. Every student artist has his or her own visual interpretation of the model that depends on the focus of the eye. This means that each drawing, though derived from the same model, will generate different aspects of emphasis which gives the drawing its uniqueness. The student artist captures the model's body structure starting with the back of head adorned with its hair style, bare shoulders and a stringed black top. The black top shows folds that depict its semi-tight fitting. The

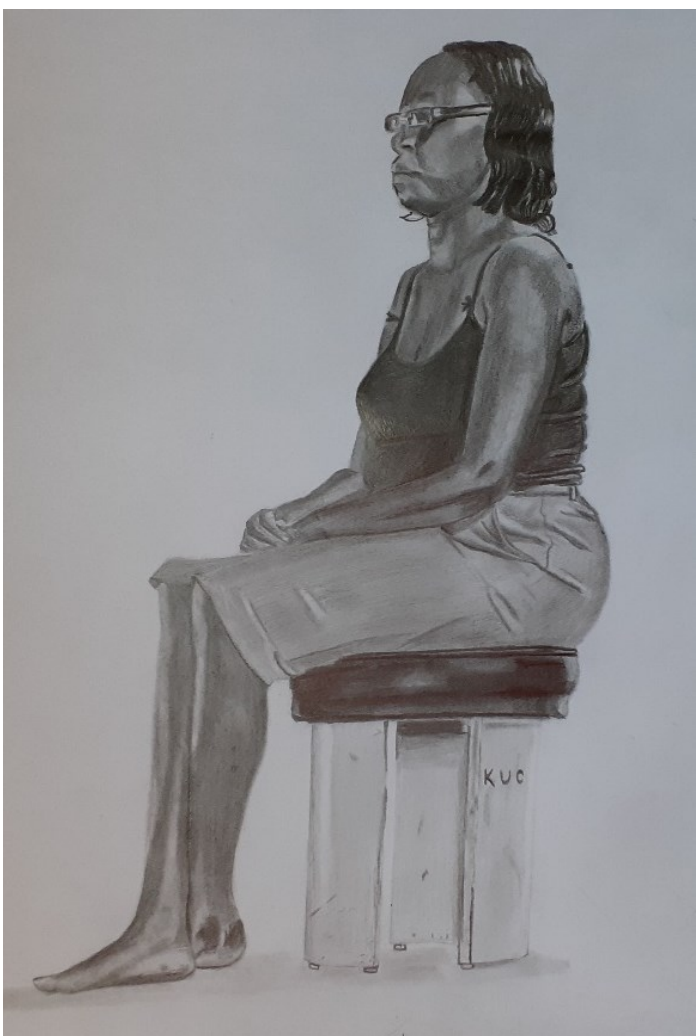

Plate 19: Mercy Mwikali (2020)

'Full figure Seated pose'

Pencil - 42 × $29 \mathrm{~cm}$

student artist captures the various space segments which are important for describing proportions. When working out proportions, one looks for major lines that demarcate segments that provide the distances that the eye looks for. For example, the segment of the exposed body gives way to the segment of the black top which extends to the segment of the grey skirt, which in turn gives way to the edge of the pouf that extends all the way to the edge of the floor. The front facing side angle (Plate 19) shows the study of the same model by a different student artist that demonstrates the same points of observation producing an almost identical structural layout of the model. The artist, however, presses her pencil a little more culminating in very pleasant pencil tones that give the drawing its character and suggests the personality of the model. The student artist also accurately studies the facial likeness of the model. 


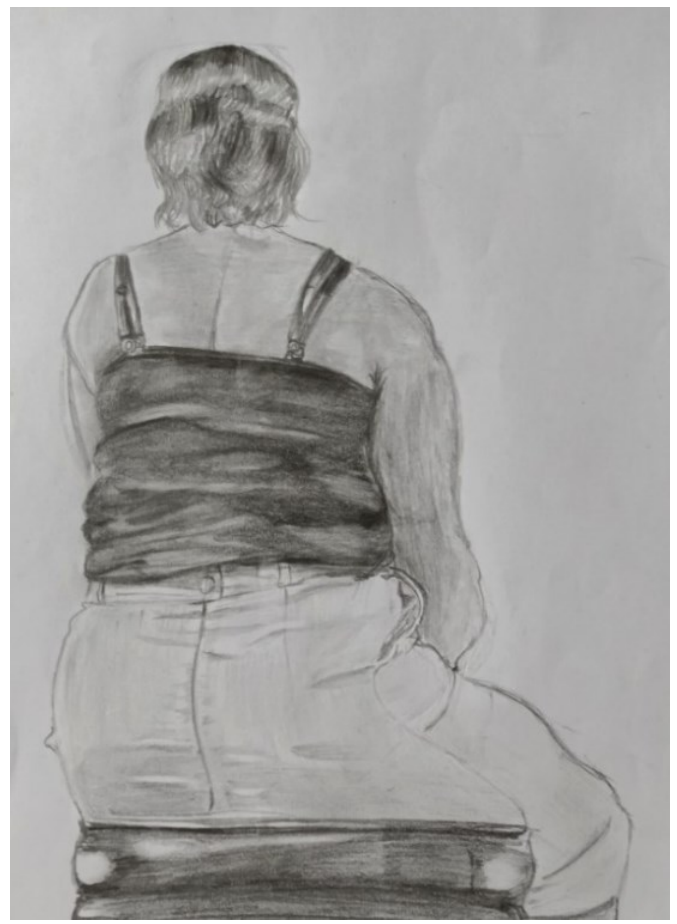

Plate 20: Ruby Moraa Rasugu (2020)

'Detail of upper back seated pose'

Pencil - 42 × $29 \mathrm{~cm}$

It can be observed from the figure drawings (Plates 20 and 21) how differently students approach figure drawing but capture essentially the same major aspects. But once they have captured what they perceive as essential focus points, they proceed to give their drawings a final finish that is executed to different degrees of finesse which underscore their innate drawing abilities. In Plate 20, the student artist captures the figure of the model indicating an understanding of the major points of observation including the back of head, shoulders, the arms, the straps of her blouse top, the black top itself, the waist marked by the beginning of the skirt and lastly the edge of the seated body. She then gives a suggestive shading of the folds that defines the shape of the body itself. There is study of symmetry; the zip line of the skirt is in line with the spine ridge of the model's body meaning that the body posture is actually aligned. The stool line is also well outlined meaning that the body sits well within its base.

In Plate 21, the drawing is similar in terms of the observed details but is executed with much more 'sense of the eye' and application of more defined pencil tones. The difference in observation is that

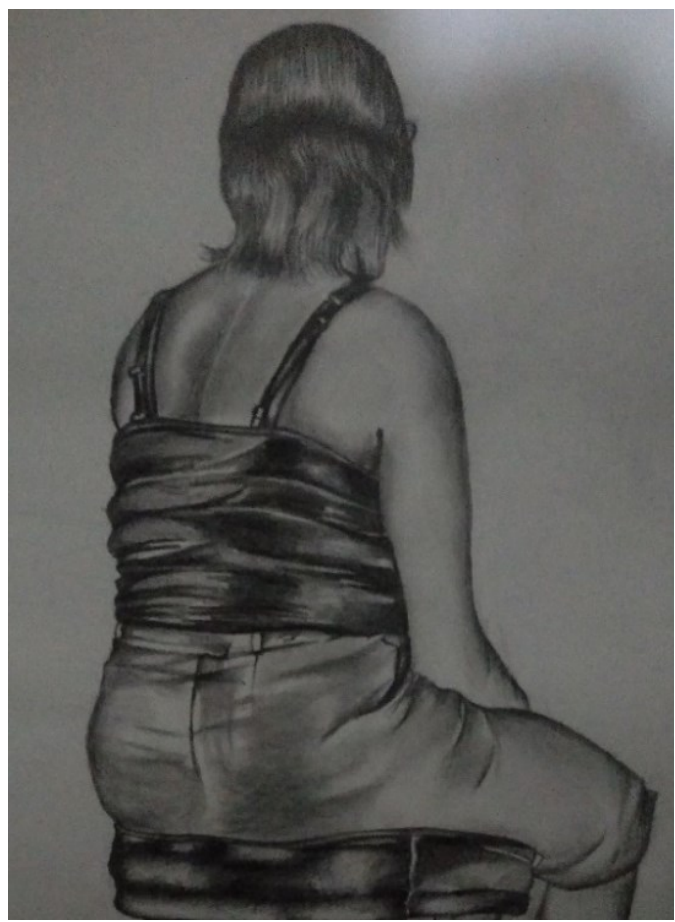

Plate 21: Olago Brian (2020)

'Detail of upper back seated pose'

Pencil - 42 × $29 \mathrm{~cm}$

the student artist in this drawing is keener on actual distances between the various parts of the body; for instance, the shoulders fall accurately on either side of the neck (which is hidden by the stretched hair) and do not extend too much from the neck making them more feminine and realistic. The arm is more accurately drawn and not a little grotesque as in Plate 20. The length of the straps of her blouse depicts the distance between the edge of her black blouse top and the shoulder line exposing a significant amount of her bare back. The student artist then observes the distance occupied by the black top down to the edge of the skirt and subsequently the distance occupied by the skirt all the way to the seated edge of the body on the stool. These are the distances one measures with the eye when drawing to work out visual calculations of proportions, and they appear different in the two drawings. The more accurately one captures such distances, the more accurate the figure appears to the eye. The student artist then proceeds to apply pencil tones suggesting the shiny blow-dried hair, the spinal ridge of the body and the various folds that describe the nature of the blouse material and how it is suspended upon the body. The folds also define the skirt and how it takes up the contours of 
the model's body. The folds are shown by varying the tones appropriately with the lightest tones indicating where light hits the fold. It can be concluded that the student artists both achieve the

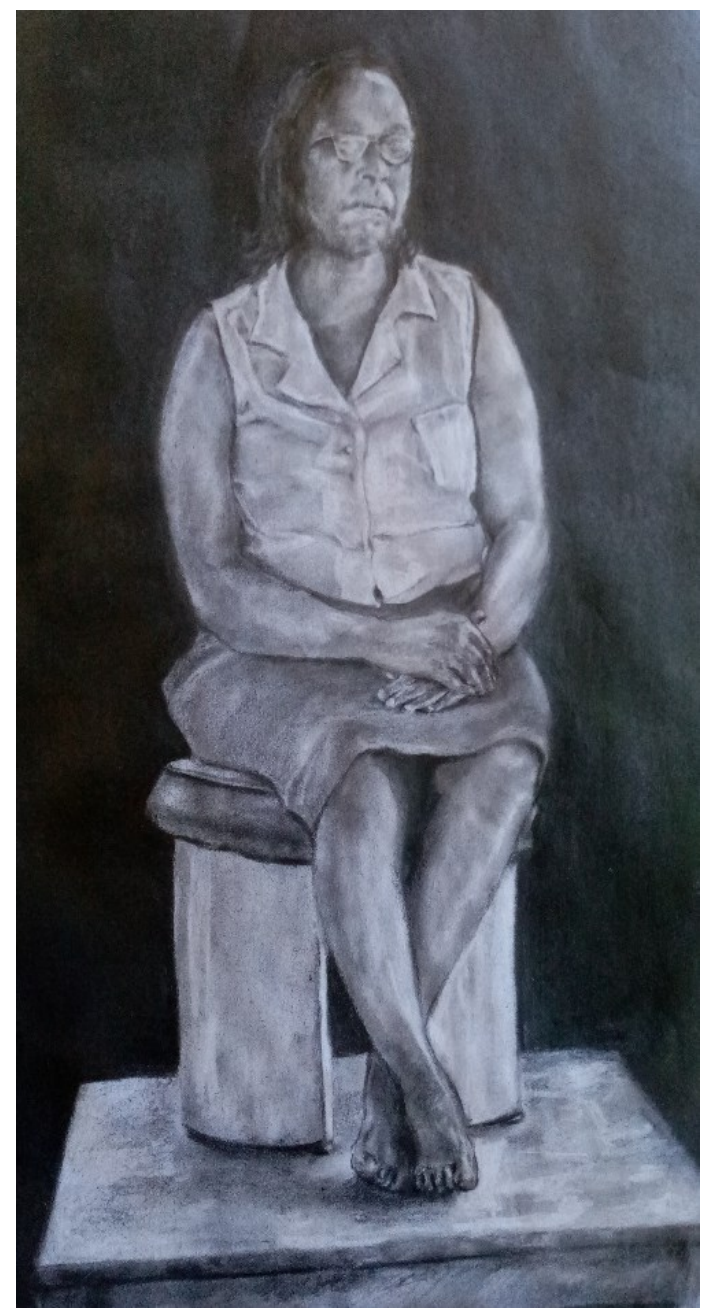

Plate 22: Samuel Muiga (2020)

'Front view seated pose'

Pencil -42 × $29 \mathrm{~cm}$

The front view seated figure (Plates 22 and 23) is often challenging to students because certain angles suggest an element of foreshortening. Students are required at this stage to be able to correctly capture the proportions of the figure as well as various details that define the body of the model including poise, facial likeness and nature of attire. When all these are successfully depicted then one achieves the 'physical character' of the model. This attainment of artistic physical character of the particular model is the ultimate objective of any life drawing since a model is a human being who bears visual purpose of the exercise but one simply 'captures' the essence of the figure while the other 'defines' more subtly the physical character of the figure through detail.

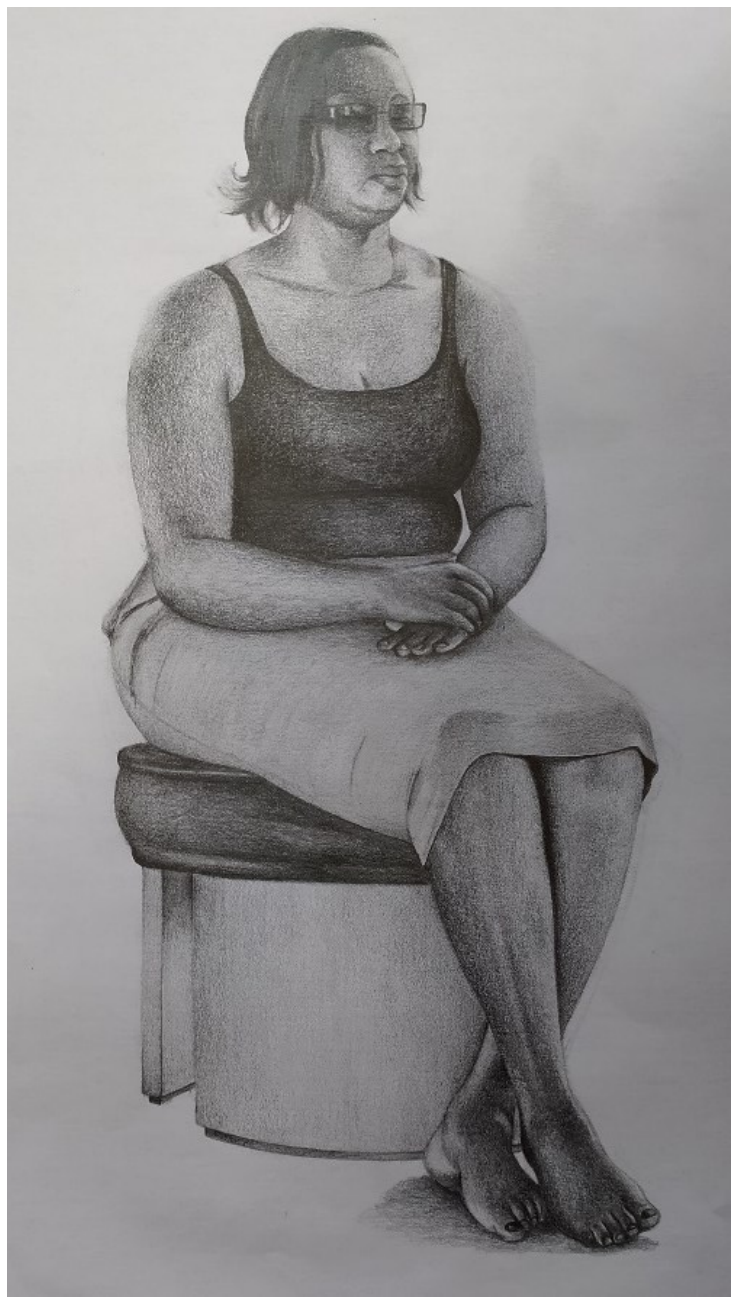

Plate 23: Mvoi Kigondu (2020)

'Front view seated pose'

Pencil - 42 × $29 \mathrm{~cm}$

unique definitive features that underscore his or her 'identity'. Subsequently, students are reminded that the joy of life drawing at this level is to capture the identity of the model and not to simply draw a wellproportioned amorphous figure drawing; at the end of the exercise the idea is that the viewer would be able to more or less identify the 'person' of the model. Both student artists capture the figure well and apply details and finish to different levels of precision. There are a few proportional issues in each of the drawings but human figure drawings are never perfectly accurate. It can be concluded that the 
student artists met the objective of this drawing exercise and that the various visual discrepancies would be addressed in subsequent drawings as they continue to draw.

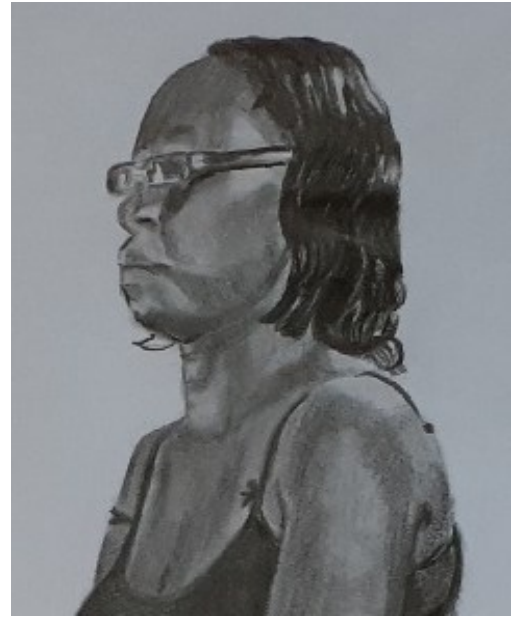

Plate 24. Mercy Mwikali (2020) Pencil- Detail of face'

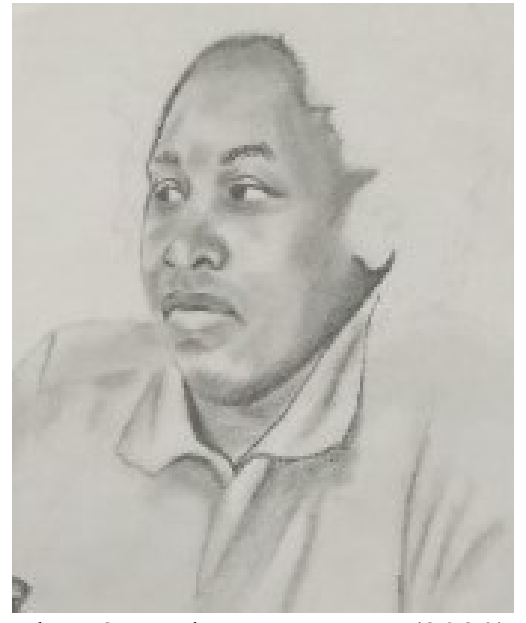

Plate 25. Edgar Keng'ara (2020) Pencil - Layout of face

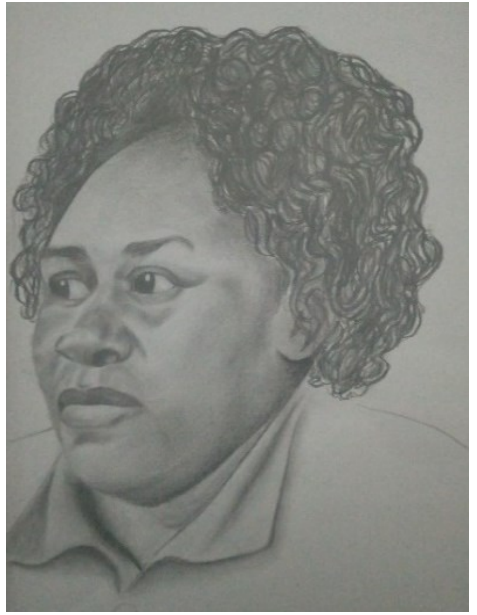

Plate 26. Edgar Keng'ara (2020) Pencil- Detail of face
Drawing of the human face is an engaging undertaking and requires time and effort. In the series of drawing exercises in this paper, the focus of the study was not specifically on the face; that would require specific exercises. The students were, however, required to create a study of the model's face in order to capture the outlay of facial proportions as part of their observational training as well as finishing their drawing. In a close-up of the actual figure drawing, the student artist (Plate 24) captures the model's face appropriately showing good placement of facial components and how the face connects with the neck, creating the pose. It is evident that the student was aware of what can be captured from the side angle and uses pencil shading effectively to emphasize upon facial characteristics through variation of tones and shining of light on various spots. The face is finished by the depiction of the textural effect of the hair all of which give it its feminine aura. Plate 25 demonstrates how some students approach the drawing of the face. The student artist makes a light suggestive shading of the face showing not only good placement of facial components but creating a likeness of the model from the onset. In human figure drawing at this stage, actual facial likeness is not a critical requirement but students are encouraged to aim to achieve some degree of likeness that emerges with more focused observation. This trains then to pick out and place facial characteristics which are unique to each individual. Plate 26 shows an addition of more detail to the face in Plate 25 including more work on the eyes, definition of the nose, shading below the eyes and inclusion of the texture of hair, giving the face more character and poise. The faces also show that students tend to apply pencil shading to different degrees of tonal value that denotes their personal level of comfort with the use of pencil. 


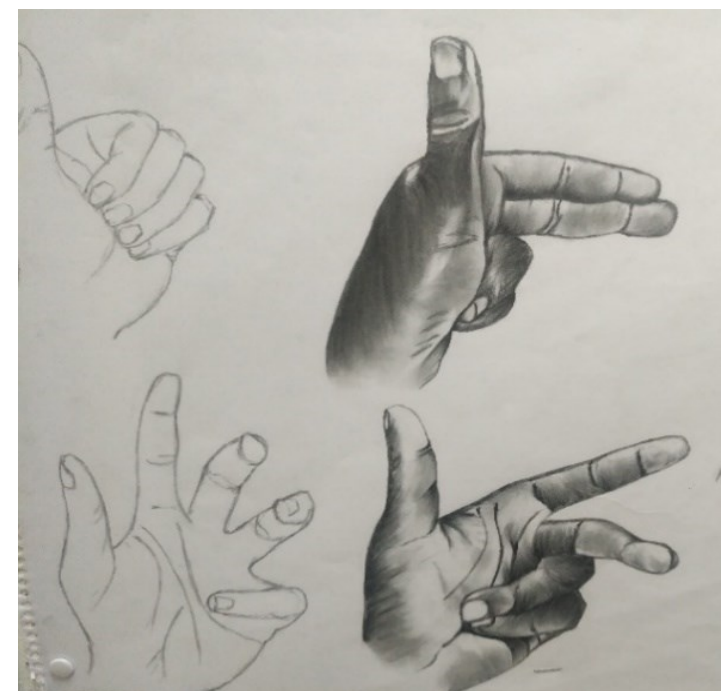

Plate 27: Stephanie Kerubo (2020)

'Study of hand gestures'

Pencil -42 × $29 \mathrm{~cm}$

Drawing of hands is very enjoyable but most students find it daunting to begin with. It is important to study hands at the same time as one studies the entire body because hands are a subset of the body and are key to defining the compatibility of body proportions. Students were required to draw various hand gestures based on their own hands and then enhance their drawings using pencil shading. The major emphasis in this series of exercises was to note the placement of each finger in the selected gesture as well as to study the finger segments and their knuckles and how they fold to create the gesture. They were instructed to note that the fingers operate through the movement of joints at the knuckles and that fingers, therefore, always fold according to their segmentation. Plate 27 is a study of the hand showing the finger segments and how they fold at the knuckles. The student artist completes the drawing by shading to emphasize the gesture. Plate 28 shows both a folded hand gesture and an open hand gesture. The idea of the exercises was to observe and study the suggested movement when the palm of the hand is folded or open. The student artist is able to capture the segments of the fingers as well as the knuckles quite accurately through focused observation of the entire hand proportions. It is likely that when this skill is applied

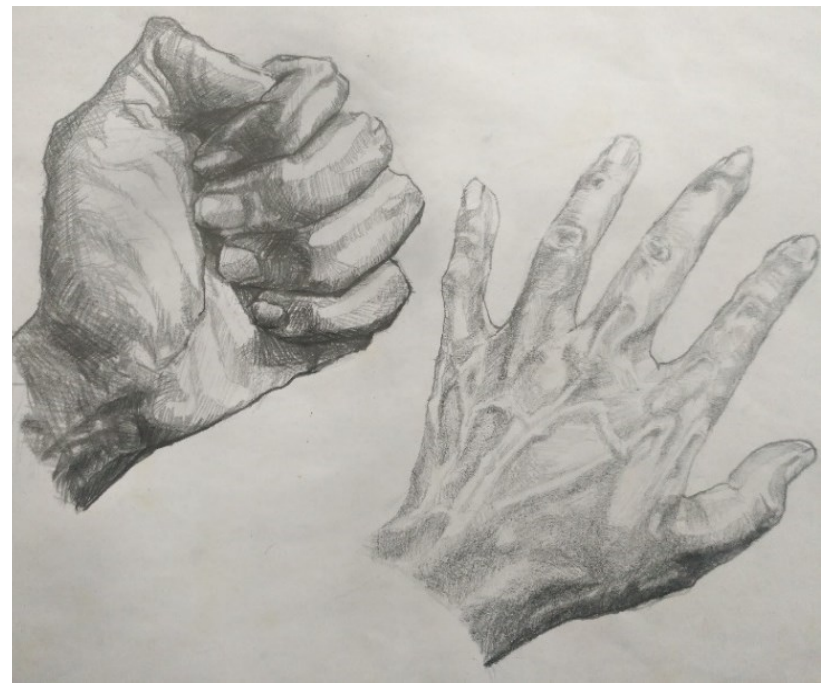

Plate 28: Samuel Muiga (2020)

'Study of hand gestures'

Pencil - 42 x $29 \mathrm{~cm}$

to the entire figure, the student will recall that the hand has its own proportional dimensions that must synchronize with those of the arm and the body at large.

Samples of the same studies are shown in Plates 29 and 30. Student artists are guided by the same principle of hand movement and how fingers shift either independently or collectively in creating a given gesture. The continued focused study and observation of segmentation and the functional role of the knuckles in the manipulation of hand movements culminated in amazing results. In Plate 29 , the student artist makes further detailed studies of the hands through shading, variation of tones and shining of specks of light which helps to emphasize the gestures. The observation of the distances on finger segments is helpful in creating the structure of each finger and thumb as a strategy of drawing proportional hands. In Plate 30, the student artist studies the stretched outer hand to capture the placement of fingers, their individual proportions and how these proportions relate, relative to each other. In the next drawing the student isolates each finger in the creation of a given action, in this case grasping of a pencil. 


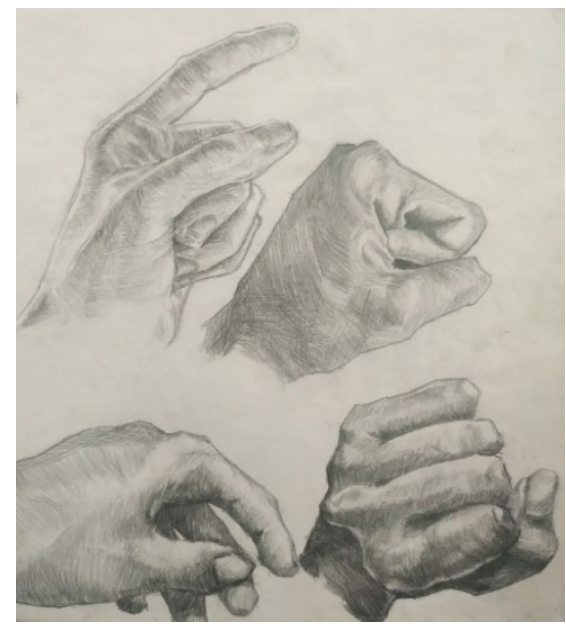

Plate 29: Samuel Muiga (2020)

'Hand drawings'

Pencil - 29 x $42 \mathrm{~cm}$

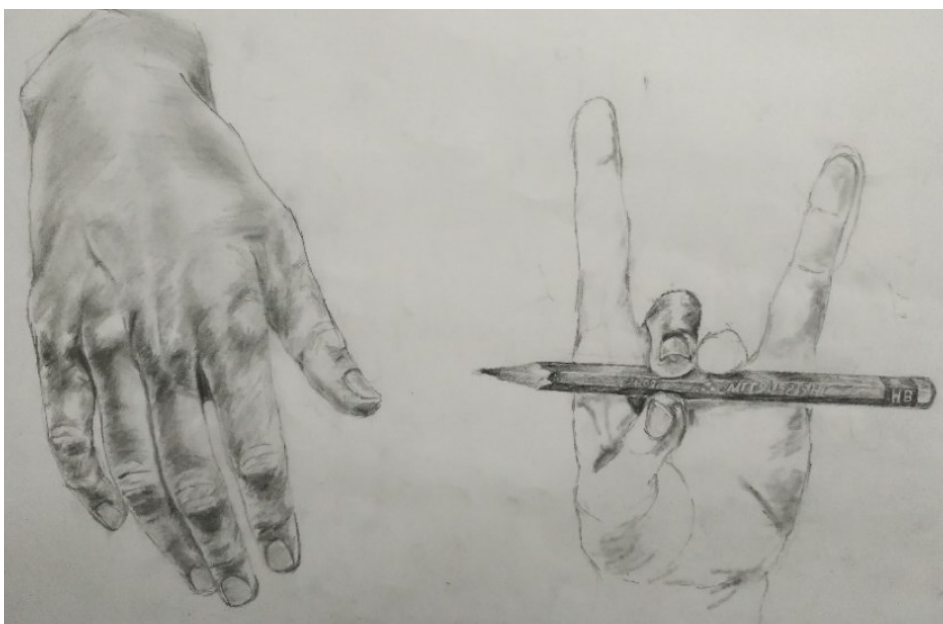

Plate 30: Orodi Otieno (2020)

'Hand drawings'

Pencil - 29 x $42 \mathrm{~cm}$
In Plates 31 and 32, the students artists explored hand gestures by making quick line sketches that depict the functional use of hands and how fingers create movement. In Plate 31 the student artist applies pencil shading to the study of a hand gesture that shows how fingers fold at their knuckle joints to create a knuckle-head fist in one drawing and crossed finger gesture on the other. It can be observed that once students observed and

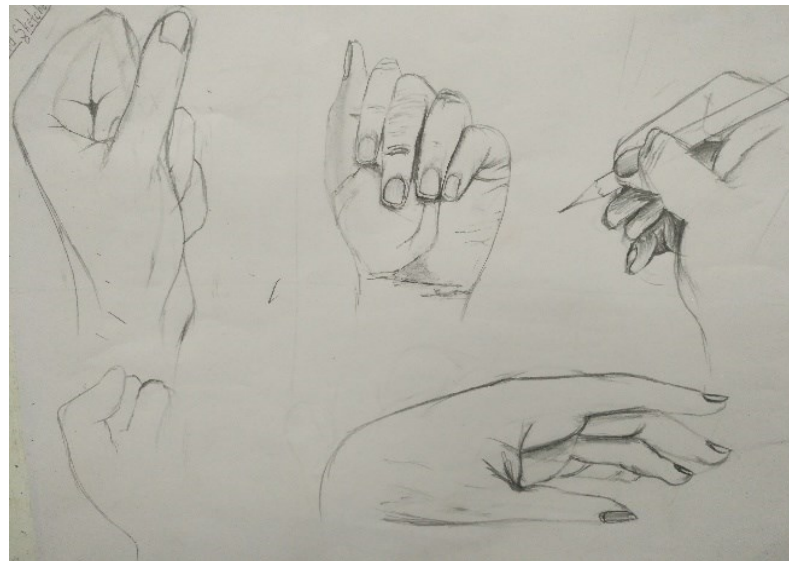

Plate 31: Stella Onguti (2020)

'Hand sketches'

Pencil - 29 x $42 \mathrm{~cm}$

It was observed that these hand drawing exercises proved helpful in directing the attention of the students to the connection between individual hand proportions and the proportions of the entire body structure. The students started to notice, for understood the functional role of fingers and the entire hand, particularly its grasping ability and flexibility of fingers, it became easier for them to attempt to draw the same from observation. Subsequently, they tried out many gestures by drawing focused line sketches where it was evident that they knew what they were looking for and wanted to ensure that the fingers looked proportional, as if to meet their functional role.

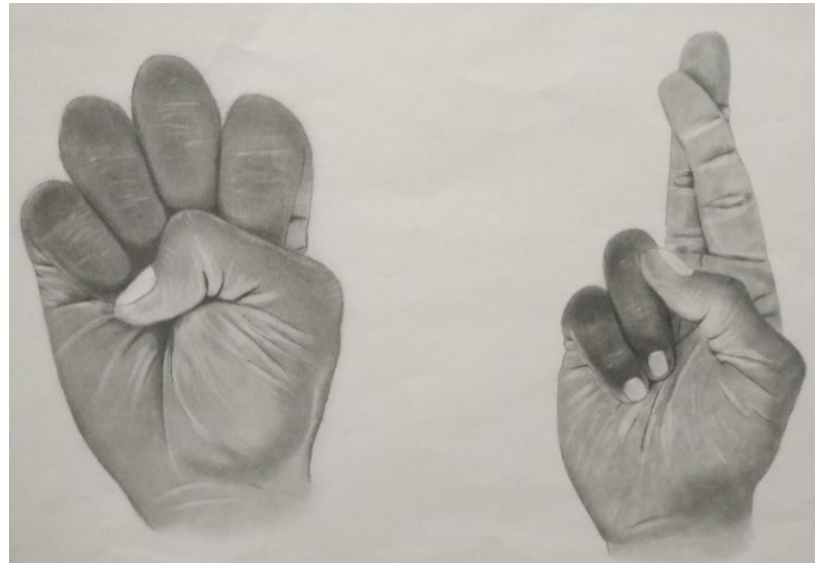

Plate 32: Edgar Keng'ara (2020)

'Hand gesture drawings'

Pencil - 29 x $42 \mathrm{~cm}$

instance, that when drawing the full human figure, the proportions of the hands must be made compatible to those of the rest of the figure for it to bear visual integrity. 


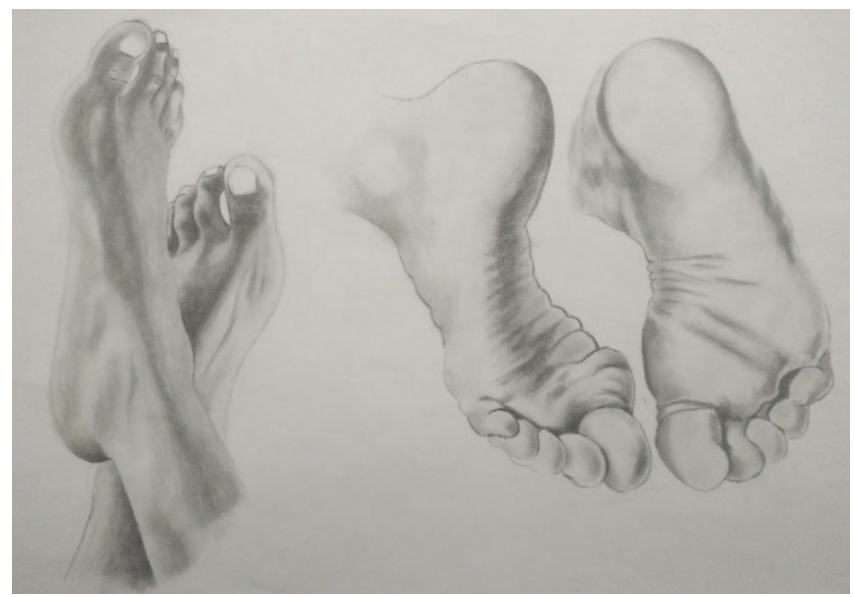

Plate 33: Edgar Keng'ara (2020)

'Study of feet'

Pencil - 29 x $42 \mathrm{~cm}$

Students were required to study feet as part of the human figure drawing. Feet are important in the way proportions fit in within the human figure since they functionally support the whole-body frame. It was earlier observed that students tend to deemphasize hands and feet in human figure drawing often resulting in a figure that looks distorted; particularly as a result of proportionately small feet or small hands. This usually occurs when students have not yet internalized the compatibility of proportions. The students studied each other's feet and were guided into observing the functional value of feet as a basis of working out the proportions of the smaller parts of the feet. The emphasis was on exploiting observational skill and avoiding a

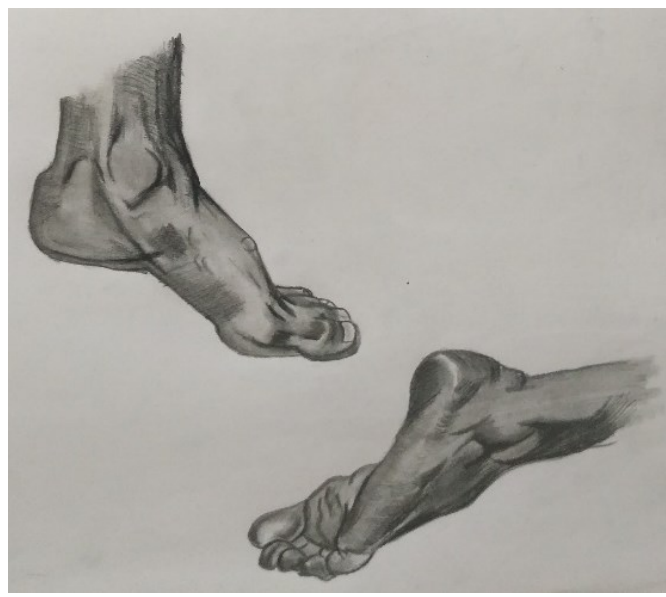

Plate 34: Mercy Mwikali (2020)

'Study of feet'

Pencil - 29 x $42 \mathrm{~cm}$

mathematical approach to this kind of drawing. The students' attention was drawn only to critical parts of the human foot to which they needed to pay particular attention, flexibility of the foot and the functional role of each part. They were told to pay attention to parts such as the big toe, the toes themselves, the little toe, ankle, sole, instep, ball, arch, bridge and heel. They were also briefly introduced to the bone and muscle structure of the foot. Much more emphasis, however, was placed on the visible and functional outer foot and its flexibility rather than the invisible inner foot since during observation, one cannot see the bones or muscles.

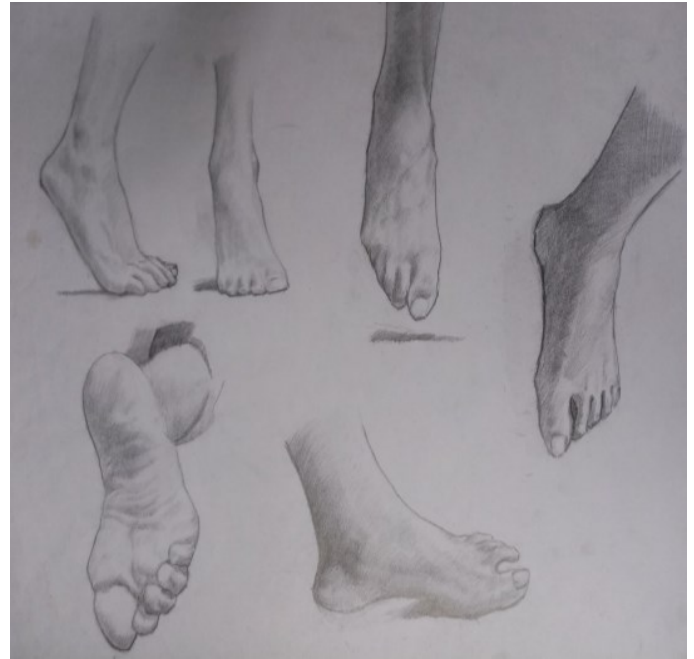

Plate 35: Samuel Muiga (2020)

'Study of feet'

Pencil - 29 x $42 \mathrm{~cm}$

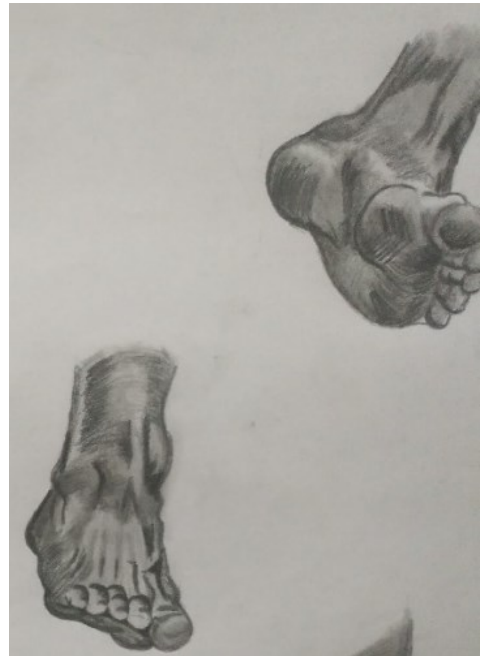

Plate 36: Mercy Mwikali (2020)

'Study of feet'

Pencil - 42 x $29 \mathrm{~cm}$ 
Plates 33 and 34 show the various studies of the feet and demonstrate that when the students' observation was well directed and focused on pertinent parts of the foot, they were able to make good drawings. Plate 33 shows the study of the crossed feet where shading is used to depict the various parts and how they interconnect. There is also the study of the underfoot that demonstrates that the student comprehends how the parts, including the sole, the arch, the placement of the big toe and the other toes all coordinate to create movement. Plate 34 shows a

\section{Overview and General Observations}

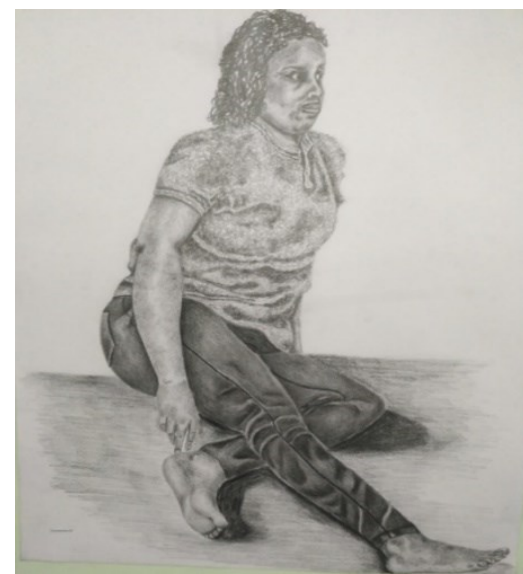

Plate 37: Maxwell Nakoche (2020) 'Propped-up seated pose' Pencil - 42 × $29 \mathrm{~cm}$

From the foregoing, it can be observed from the featured drawings in this paper that: -

- Student artists in their second year undertaking their first human figure drawing lessons were able to draw relatively accurate human figure drawings of the model standing before them, but accomplished them to different degrees of shading and detailing.

- Student artists were able to continuously observe the model and depict the interrelationships between individual parts of the body, their proportions, distances and shapes that are synonymous with the holistic human figure.

- The students executed their pencil shading very well and used it to enhance their drawing and make the model come to life. The shading also helped them emphasize the attire on the model. clear attempt to depict muscle coordination of the foot and how this enables the foot to twist and turn. The other drawings (Plates 35 and 36) are studies of flexibility and movement with the use of pencil shading to depict muscle coordination. The drawings demonstrate that although the student artists were still polishing their ability to depict correct proportions of the foot, they had a clear idea of what they were looking for as they studied the foot and its components as well as its stabilizing role.

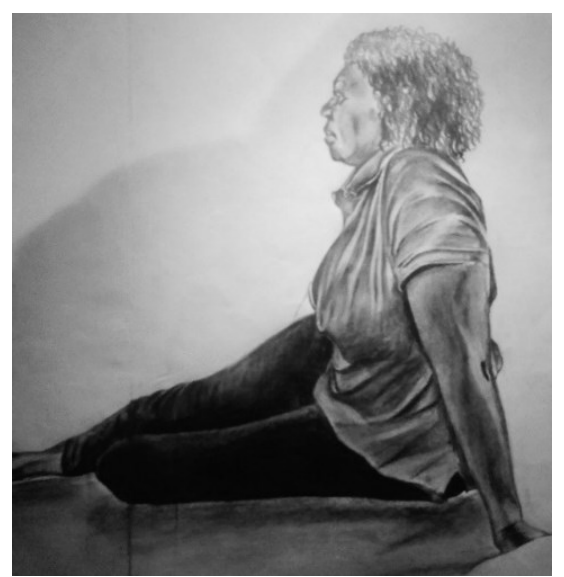

Plate 38: Brian Olago (2020)

'Propped-up seated pose'

Pencil - 42 x $29 \mathrm{~cm}$

- The study of folds on the attire proved helpful in depicting the notion of shifting movement in their drawings which showed how each part of the body contributes to body posture and proportions that balance the body. For example, the study of folds on the model's trouser (Plate 37) helps to depict a tight-fitting jean that denotes a straight stretched leg; the closely gathered folds on her blouse depict a relaxed seated position from that angle. However, the folds on the model's blouse (Plate 38) direct the eye towards the propped up left shoulder which exerts all the upper body weight on the left hand which is pegged on the ground and, therefore, supports the seated position. Without the inclusion of folds as a component of drawing, the nature of the pose or body posture would be harder to identify. 
- Prior exposure to drawing enabled the student artists to embark straight on the human figure drawing itself without spending too much time on initial stages of layout such as contour or gesture drawings. However, initial two to five minutes exercises helped them to configure quick proportions that proved useful in the more prolonged poses of which they were required to make more detailed studies.

- When students referred to the proportions based only on observing the human skeleton or perusing through the human anatomy layout chart, they were not able to commensurately articulate the proportions in their drawings. This can be interpreted that they were not yet able to associate the bone structure with its muscle cover as a viable 'guide' towards articulating proportions of the human form.

- When students' attention was drawn towards the focused observance of proportions based on the actual physical proportions as observed on the real-life reference model, they were able to figure out how proportions interrelate. It was presumed that this was because in this case, the proportions were real and tangible. As they drew and observed the model in rhythmical eye/pencil interaction, they were able to work out how parts of the human body interrelate for them to make both 'functional' and 'visual sense'. Ultimately the proportions in the students' drawings were better articulated as they became increasingly aware upon each exercise, that individual parts of the body do not exist or function independently but as part of a holistic entity. When they were encouraged to observe this notion of holistic entity in the application of proportions in their drawings, they started to determine for themselves which part of that entity was not fitting well with the others. This was evident when they held up their work at certain intervals to see which part of their drawing was out of sync with the others. This paper contends that with only a little guidance where necessary, it is extremely important for students to be left to work out this 'principle of holistic interrelation' for themselves in order to internalize its essence. For instance, when students were told to hold out and critique their own work at given intervals, most were able to readily point out which parts of their drawings appeared off the mark in terms of proportions, even though they were still not able to immediately rectify them. They were able to tell, for instance, that the hand appeared too small compared to the rest of the arm, or that the shoulders were too broad for the neck, or fingers were too small for the entire body; or that the feet were too small for the body frame. This was a critical development in the acquisition of skill because it indicated that they were aware of or had internalized the interrelationships between parts of the body that ensured they were proportional to each other. They were then encouraged to rectify the respective visual anomaly as identified, by making the necessary adjustment until they were satisfied that the proportions were acceptable to the eye. It must be emphasized that this is not easy and it takes time to develop the boldness to make these adjustments. For example, though the student shows adequate skill and has shaded the drawing commendably (Plate 39), it bears obvious proportional problems. It is certain that the feet would not, in real life, be able to support the weight of the body; and the hands and fingers are too small for the arms. These anomalies in proportions were not rectified earlier in the line drawing stage since the exercise was continuous and uninterrupted and was designed to test their individual confidence. It emerged that when their work was shaded and finalized but still showed some areas of contention, these areas became more glaring and unforgettable. The students hence tended to look out for those areas in subsequent exercises. The student in the case of Plate 39 would now pay much more attention to feet and hands in subsequent drawings to ensure holistic figure alignment.

- Students were attracted to the notion of facial likeness and wanted to depict the model in their likeness as closely as they could. Students were successful in doing this to different degrees. It can be observed that those who got the facial likeness correct also studied the details of the model's body shape correctly. 


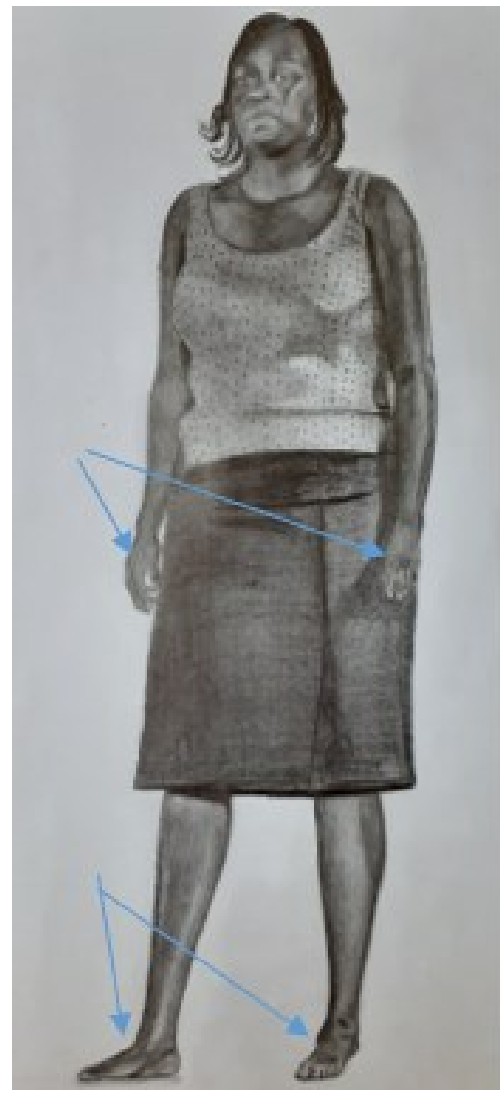

Plate 39: Mercy Mwikali (2020) 'Detail of upper back seated pose' Pencil - 42 × $29 \mathrm{~cm}$

In Plate 40 the student artist gets the shape of the body basically correct including better-rendered feet, hands and fingers. The shading is well executed and shows good attention to detail, but the face is a little distorted because of an aspect of misplaced emphasis when shading. Such are the mistakes students often make as they learn but they are easily rectified with time and practice and are seldom ever repeated. This is part of the development of personal objectivity in assessing one's own work.

\section{CONCLUSION}

The following conclusions can be derived from the foregoing:

\section{Acquisition of Skill}

That students undertaking this second-year level drawing unit are able to create good human figure drawings that demonstrate a growing

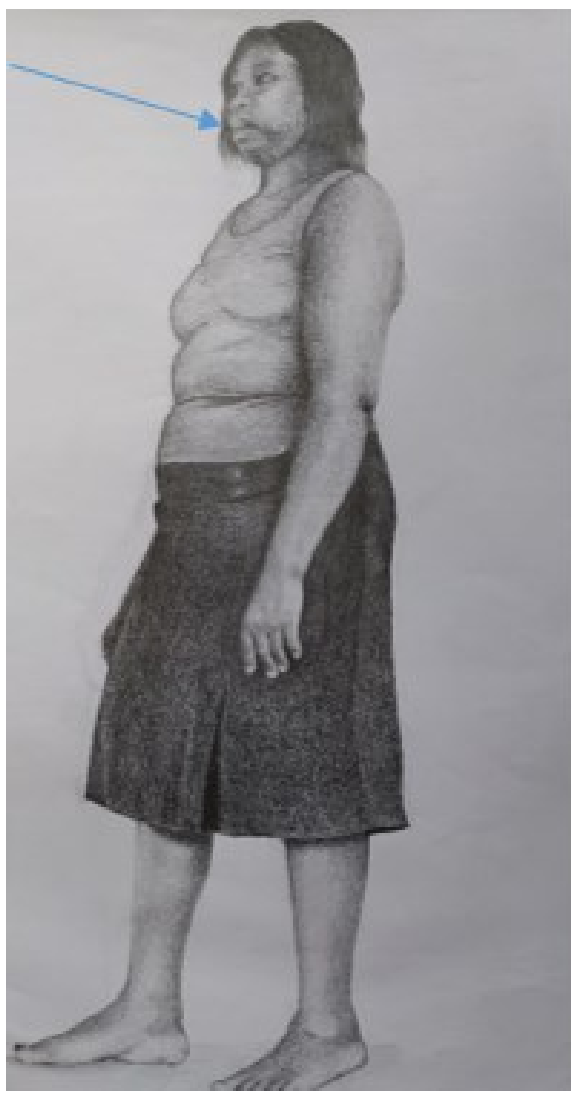

Plate 40: Mvoi Kigondu (2020)

'Detail of upper back seated pose'

Pencil - 42 × $29 \mathrm{~cm}$

comprehension of intricate proportions that define the human figure. This is indicative that they are able to gain considerable observational and drawing skills with the potential for further development with time and practice. This is in view of the fact that the acquisition of skill in life drawing, as is in other types of drawing, is a process. This is deemed useful for their ability to subsequently express themselves in any other discipline of their choice.

\section{Prior Exposure}

That prior exposure to draw, particularly in the introductory stages, plays a critical role in exercises that involve human figure drawing. That since drawing is a continuous process, the more students are exposed to formative drawing exercises, the more they are prepared to tackle more challenging work including shading. In the work featured in this paper, students did not spend much time on exercises such as linear construction, study of the function of joints, contour or gesture drawing, yet 
they were able to produce good drawings. This means then that their formative prior exposure played a significant role in preparing them for the drawings in this unit.

\section{The Use of a Model}

The involvement of a model is a critical component in the drawing of a human figure. From this study it is evident that the observation of the various components of the human body is more focused and enhanced when viewing an actual living person or real-life reference than otherwise.

\section{The Usefulness of Musculoskeletal Reference in Human Figure Drawing}

Reference to the rather scientific layout of the musculoskeletal anatomy does not necessarily ensure that students draw the human figure accurately. It is, however, acknowledged to be a very good guide to how parts of the human body interrelate and function as well as a good guide to their proportions. This paper concludes that this anatomical referencing should be accompanied by the focused observation of the real-life reference (or model) where students are able to associate the dissected anatomy of bone and muscle structure, to the tangible human model posing before them in order to work out and visually render outer proportions.

\section{The Model as a Focal Point of Engagement}

Observing the same model as the focus of reference makes students observe certain pertinent 'real-life visual cues' that help them to construct proportions and draw other details that relate to the individual model. This is evident in the rendition of the holistic form of the model, the proportions of the respective body parts, the attire, and pencil application on the shading of the drawings. Students are also then able to compare their work and peer critique themselves which adds to their individual artistic development.

\section{The Visual/Functional Principle of Deriving Proportions}

When students' attention is directed towards the interrelationships of the various parts of the model's body from the perspective of their functional value, it helps them to better work out their proportions relative to each other from the perspective of their visual roles. For example, the head rotates upon the neck and the neck rests on the shoulders in a defined way; the functional value of the head dictates that it must connect to the neck proportionately for this function to occur. Likewise, the functional value of the neck must synchronize with the size of the shoulders for it to function accordingly which means that these parts have a definitive way in which their proportions must relate and interlock. This principle applies to all body parts, which means that the study of proportions is not just carried out as an artistic embellishment in the construction of a human figure, or merely to satisfy the artistic hand, but also as an observation of functional value. When this is emphasized in the drawing class, the students are more careful to try to observe the synchrony between functional value and visual value. Another example that shows the importance of this visual/functional relationship in life drawing is when students are 'advised' that feet must carry the weight of the body. Hence, it is determined that the functional value of feet is to support the entire body mass otherwise the model will be unable to stand. If the feet appear too small in the drawing, then there occurs an obvious visual discrepancy that must be rectified to reflect the functional role of feet. This functional value is in turn seen in relation to the bone and muscle structure of the rest of the legs all the way up to the stabilizing effect of the hips. Therefore, when students bear this principle in mind as they draw their human figure from head to toe, there is a high probability that they will strive to depict proportions correctly as is evident in the drawings featured in this paper.

\section{Focused Observation}

When students' observation is well directed and focused on pertinent parts of the human body as shown on the model, they are able to make comparatively better drawings. Students often 'look' at the model but fail to 'see' and hence carefully 'observe' what they are looking at, missing important cues that are right before them. But when there is some purpose in their observation, then they form an association between the essence of what they observe and the drawing they make. This is not unusual and often makes the difference between the better endowed students and others 
who require more time and practice to improve their drawings.

\section{The Concept of Visual Logic}

This paper posits that the concept of visual logic is very useful in attracting the attention of students towards the purpose of their observation of the model before them. A brief discussion prior to the drawing exercise is an ideal way of directing the purpose of observation. Students may see the need for observation because it is physical and obviously necessary, but they may not comprehend the purpose. An important logical point to underscore is that the human figure is already beautifully crafted and hence a certain visual logic already exists and is obviously observable. In attempting to draw the human figure, therefore, one is only attempting to align his or her drawing to conform to this logic. This means that there is a unique relationship between parts of the human body that remains constant and holistically make the body appear 'normal' to the eye. Any interference with this relationship between various parts would render the body 'unhuman' just as it causes indignation in a drawing. When students are introduced to this concept, they become aware of the usefulness of their observation; their observation becomes purposeful and even though they still may not draw proportions correctly in the formative stages, they become aware of their shortcomings even before these are pointed out to them by other parties. For example, within the segments of a human figure, the arms end at some point above the knee line when a model is standing straight; there is, therefore, no reason to draw arms that end at the waist line since that bears no visual logic. It is known that there is a relationship between the thigh bone (femur) and the lower leg bone (tibia) both of which determine the length of the entire human leg and together with muscle tissue and joints, construct the shape of the leg. Any misrepresentation of this relationship will translate into either short or elongated legs which deconstruct the visual logic that denotes the lower body.

\section{Facial Likeness}

Students' interest in depicting subtle facial likeness (even though it was not a major objective of the drawing exercises) can be attributed to the desire to capture the personality of the model. Since the model is a specific human being with an innate character, facial characteristics become important in defining that individual. Students then tend to associate the notion of character to the accurate depiction of facial likeness. The more they are successful in depicting facial likeness, the more they feel they have unveiled and defined the model's character or personality; and it generates immense personal satisfaction. When the students fail to portray what they judge to be satisfactory facial likeness and body shape, they feel like they have failed the model even though the drawing itself may be satisfactory to the eye. By association, therefore, a good drawing that lacks facial likeness amounts to a failed drawing.

\section{Development of Personal Objectivity}

Although it is appropriate to give students due guidance in observing and interacting with the model during the drawing process, students tend to ultimately develop better drawings when they are left to isolate and identify their own areas of weakness in their drawings. This leads to very useful 'self-objectivity'. When students themselves identify areas of weakness, they purposefully focus on those areas in subsequent drawings to eliminate the visual anomaly. When on the other hand they have their mistakes constantly pointed out to them, they feel artistically patronized which hinders their ability to focus on pertinent areas, which then slows them down. This is mainly because it erodes their confidence in their own ability to observe and draw.

\section{REFERENCES}

Jordan, C. (2017). Figure drawing: Poses, Gestures \& Lessons for the Beginner'. Retrieved on December 12, 2020 from Artistnetwork.com, https://www.artistsnetwork.com/artmediums/drawing/figure-drawing/

Jordan, C. (2018). Figure drawing basics: Costumes, Clothes or Nothing at all'. Retrieved on December 12, 2020 from Artistnetwork.com, https://www.artistsnetwork.com/artmediums/drawing/drawing-basics-costumesclothes-or-nothing-at-all/

Li, M. (2019). What is life drawing and its benefits. Retrieved on December 5, 2020 from 
Maryliart.com, https://maryliart.com/what-islife-drawing-and-its-benefits

Medlej, J. (2013). Human Anatomy Fundamentals: Basic Body Proportions. Retrieved on December 4, 2020 from Design.tutsplus.com https://design .tutsplus.com/articles/human-anatomy-fundame ntals-basic-body-proportions--vector- 18254

Mitchell, M. (2013). The importance of life drawing in Art. Retrieved on December 11, 2020 from Markmitchellpaintings.com, https://www. markmitchellpaintings.com/blog/the-importanc e-of-life-drawing-in-art/

Swinton, D. (2018). Seven reasons why Figure Drawing is important for every artist. Retrieved on December 5, 2020 from Swintonart.com https://www.swintonsart.com/post/7-reasonswhy-figure-drawing-is-important-for-everyartist 